\title{
On the quality of the Nimbus 7 LIMS version 6 ozone
}

\section{for studies of the middle atmosphere}

\author{
Ellis Remsberg, ${ }^{\mathrm{a}, *}$ \\ Gretchen Lingenfelser ${ }^{\mathrm{b}}$ \\ Murali Natarajan ${ }^{\mathrm{a}}$ \\ Larry Gordley ${ }^{\mathrm{c}}$ \\ and
}

Earl Thompson

${ }^{a}$ NASA Langley Research Center, Science Directorate, Mail Stop 401B, Hampton, VA 23681, USA

${ }^{\mathrm{b}}$ SAIC, Incorporated, 2 Easton Street, Hampton, VA 23661, USA

${ }^{\circ}$ GATS, Incorporated, 11864 Canon Blvd., Suite 101, Newport News, VA 23606, USA

For submission to Journal of Quantitative Spectroscopy and Radiative Transfer March, 2006

${ }^{*}$ Corresponding author. Tel.: +1-757-864-5823; fax: +1-757-864-6326

E-mail address: Ellis.E.Remsberg@nasa.gov 


\section{Abstract}

The Nimbus 7 Limb Infrared Monitor of the Stratosphere (LIMS) radiance profile dataset of 1978/79 was reconditioned and reprocessed to Version 6 (V6) profiles of temperature and species that are improved significantly over those from Version 5 (V5). The LIMS V6 dataset was archived for public use in 2002. Improvements for its ozone include: (1) a more accurate accounting for instrument and spacecraft motion effects in the radiances, (2) the use of better spectroscopic line parameters for its ozone forward model, (3) retrievals of all its scans, (4) more accurate and compatible temperature versus pressure profiles (or T(p)), which are needed for the registration of the ozone radiances and for the removal of temperature effects from them, and (5) a better accounting for interfering species in the lower stratosphere. The retrieved V6 ozone profiles extend from near cloud top altitudes to about $80 \mathrm{~km}$ and from $64 \mathrm{~S}$ to $84 \mathrm{~N}$ latitude with better sampling along the orbit than for the V5 dataset. Calculated estimates of the single-profile precision and accuracy are provided for the V6 ozone from this study. Precision estimates based on the data themselves are of order $3 \%$ or better from 1 to $30 \mathrm{hPa}$. Estimates of total systematic error for a single profile are hard to generalize because the separate sources of error may not all be of the same sign and they depend somewhat on the atmospheric state. It is estimated that the V6 zonal mean ozone distributions are accurate to within $\pm 9 \%$ to $\pm 7 \%$ from $50 \mathrm{hPa}$ to $3 \mathrm{hPa}$, respectively. Effects of a temperature bias can be significant and may be present at 1 to $2 \mathrm{hPa}$ though. There may be ozone biases of order $10 \%$ at those levels due to possible biases of up to $+2 \mathrm{~K}$, but there is no indication of a similar problem elsewhere in the stratosphere. Simulation studies show that the LIMS retrievals are also underestimating slightly the small amplitudes of the atmospheric temperature tides, which affect its retrieved day/night ozone differences. There are small biases in the middle to lower stratosphere for the ascending versus descending node LIMS ozone, due principally to not accounting for the asymmetric weighting of its radiances across the tangent layer. The estimates of total accuracy were assessed by comparing the daily zonal mean LIMS ozone distributions against those from the Nimbus 7 SBUV Version 8 (V8) dataset for the same period. Generally, the LIMS V6 ozone agrees well with SBUV, except perhaps in the tropical lower stratosphere where the LIMS ozone is less. Still, the accuracy for LIMS V6 ozone in the lower stratosphere is improved over that found for LIMS V5, as indicated by several LIMS comparisons with ECC ozonesonde profiles. The LIMS V6 ozone 
is considered especially suitable for detailed studies of large-scale stratospheric processes above the 100$\mathrm{hPa}$ level. Comparison of diurnal, photochemical model calculations with the monthly-averaged, upper stratospheric ozone observed from LIMS V6 indicates only a slight ozone deficit for the model at about 2 $\mathrm{hPa}$. However, that deficit exhibits little to no seasonal variation and is in good agreement with similar model comparisons for a seasonal time series of ozone obtained with ground-based microwave instruments. Because the LIMS V6 ozone in the lower stratosphere has improved accuracy and sampling versus that of V5, it should now be possible to conduct quantitative studies of ozone transport and chemistry for the northern hemisphere, polar stratospheric winter of 1978/79 - a time period when the catalytic loss of ozone due to reactive chlorine should not have been a major factor for the Arctic region.

Keywords: Satellite; Ozone; Infrared limb-sounder; Stratosphere 


\section{Introduction}

The historic, Nimbus 7 Limb Infrared Monitor of the Stratosphere (LIMS) dataset was obtained from

October 25, 1978, through May 28, 1979. Its daily data extended from $64 \mathrm{~S}$ to $84 \mathrm{~N}$ latitudes and are available at two local times per latitude (about $1300 \mathrm{hrs}$ and $2300 \mathrm{hrs}$ at the Equator). The Version 5 (V5) LIMS profile data products were archived in 1983 and are described in Gille and Russell [1] and references therein. Since that time, significant improvements have been realized in the spectroscopic parameters that were used to process the V5 dataset, and there were other changes in the knowledge of the orbital attitude that affected the retrieval of its temperature versus pressure (or $T(p)$ ) profiles and the registration of the radiance profiles with pressure for all its channels. For these reasons the LIMS dataset was reprocessed to a Version 6 (V6) and then archived at the NASA Goddard Distributed Active Archive Center (DAAC) in September 2002. A description of the improvements that were applied in its processing was given in Remsberg et al. [2], along with a brief assessment of the quality of the V6 T(p) and geopotential height profiles. This paper characterizes the improvements that were obtained for the V6 ozone.

Fig. 1 is the zonal-mean distribution of descending node (or nighttime) V6 ozone mixing ratio (in ppmv) for January 1979. Its distribution extends from cloud tops to about $0.01 \mathrm{hPa}$ (near $78 \mathrm{~km}$ ), whereas the V5 data extended no higher than the 0.07 to $0.05 \mathrm{hPa}$ level. One can see that ozone is increasing toward its secondary maximum near the mesopause. There are also indications of excess (spurious), ozone at about $60 \mathrm{~S}$ and $0.01 \mathrm{hPa}$, most likely due to contaminating emission from polar mesospheric clouds (PMC) that often occur at high latitudes in summer. The corresponding January distribution of ascending node ozone (or daytime results away from high northern latitudes) is very similar in the stratosphere to that of Fig. 1 but has smaller values in the low to mid mesosphere (not shown). However, the daytime, mid-mesospheric values are still larger than expected from considerations of the standard, diurnal ozone photochemistry because its V6 ozone radiance profiles have not been corrected for the added emission from the vibrationally-excited states of $\mathrm{CO}_{2}$ and $\mathrm{O}_{3}$ that are pronounced in the presence of sunlight. Other non-local thermodynamic equilibrium (non-LTE) effects due to 'Earthshine' affect the retrieved daytime and nighttime ozone of the mid-mesosphere, but to a much smaller extent than the solar excitations of daytime. 
In general, the LIMS V6 data are not recommended for quantitative studies of ozone in the mesosphere until corrections for those effects can be developed and applied.

The vertical spacing of the profile points has been decreased for V6 without degrading the data precision appreciably, and the frequency of the retrieved profiles along an orbit has been more than doubled for the V6 dataset compared with that for V5. These improvements in spatial sampling are providing more detail about the effects of large and medium scale transport on ozone. Natarajan et al. [3] showed that the V6 upper stratospheric ozone of Fig. 1 for January is close to that predicted from a diurnal photochemical model based on the estimated atmospheric amount of chlorine source molecules present in 1979 .

This paper contains an assessment of the quality of the individual LIMS V6 ozone profiles. Section 2 briefly reviews the improvements in the forward model for the radiances in the LIMS ozone channel. It also describes the criteria that were used to detect the effects of cloud top emission in the ozone profiles and to remove those data, prior to their submittal to the archive. Section 3 provides the estimates of precision and accuracy for the individual V6 profiles. Residual biases that remain and are apparent from the ascending versus descending (or A/D) differences for the zonal mean ozone distributions are discussed in Section 4. Next, the estimates of profile accuracy are assessed in Section 5 by how well the V6 ozone distributions and profiles agree with those from the SBUV Version 8 (V8) dataset. Section 6 shows LIMS V6 comparisons with several ECC sonde ozone profiles that indicate good agreement down to the 100-hPa level for middle latitudes of the northern hemisphere. These first comparisons with the sondes are intended to quantify the LIMS results for the lower stratosphere, although the findings are admittedly not representative of the full range of retrieved LIMS ozone profiles (tropical to high latitude and for polar winter conditions). Section 7 provides seasonal variations of the LIMS V6 ozone of the upper stratosphere and comparisons of its monthly-averages with those from a diurnal photochemical model. These updated findings are compared with some previous estimates of the seasonal cycle amplitude for ozone from observations. Section 7 also contains a sample polar plot of ozone at $10 \mathrm{hPa}$ for January 27 , 1979, in order to indicate the amount of detail that one can expect for studies of the horizontal transport of ozone at 
middle and high latitudes of the winter hemisphere. The concluding section summarizes the improvements

for the LIMS V6 ozone. 


\title{
2. Improvements in the LIMS V6 ozone algorithm
}

\author{
a. Forward model
}

Tables of emissivity growth versus pressure, mass path, and temperature were used for the forward model of the radiances in the LIMS ozone channel in the manner of Gordley and Russell [4]. Smith and Gordley [5] showed that inaccuracies in line halfwidth can have a significant effect on the retrieved LIMS ozone of the middle and upper stratosphere. New tables were created for V6 using the improved HITRAN 96 line parameters [6] but with an important modification. The air-broadened halfwidths for $v_{3}, v_{1}$, and their overtone and combination bands were increased by $17 \%$ to account for the differences between the calculated values and those measured by Smith et al. [7, see their Fig. 4a]. Specifically, line widths in HITRAN 96 were modified if they had rotational quantum numbers J" less than or equal to 20 and K" from 3 to (J" - 1). About 9,000, primarily strong lines, out of 60,000 lines were modified in this way. More recent versions of HITRAN incorporate changes in the halfwidths for all the lines based on updated molecular model calculations for ozone, but their net effect for the limb emission should be similar to the first-order modifications that we employed for V6. The modified halfwidths lead to retrieved V6 ozone mixing ratios that are smaller than the V 5 values by about $5 \%$ in the upper stratosphere.

All the important 'hot' bands of ozone were included in the emissivity tables for the LIMS V6 forward model. Those 'hot' bands and the combination bands of the $v_{3}$-band of ozone depart from local thermodynamic equilibrium (LTE) above about $50 \mathrm{~km}$, especially during daytime. The non-LTE emissions from the interfering, 'hot' $\mathrm{CO}_{2}$ laser bands were not included in the generation of the emissivity tables for the ozone channel. But, Edwards et al. [8] showed that their omission is not a problem, except above about $60 \mathrm{~km}$ during daytime. As indicated earlier, the LIMS V6 retrieved daytime ozone is not very accurate for the mesosphere for those reasons, but could be improved using the non-LTE radiance models of Mlynczak and Drayson [9]. It is noted that their approach has been applied to the retrieval of the 9.6-micrometer ozone being obtained from the SABER instrument, which was launched on the TIMED satellite in December 2001 and is based on the heritage from the LIMS experiment [10]. 
Improvements in knowledge of the orbital attitude for the spacecraft have led to minor but important changes in retrieved T(p) across the domain of the LIMS V6 dataset and in the pressure registration of the ozone radiance profiles. Corrections for the orbital attitude and spacecraft motion effects were applied to all the radiance profiles, based on two empirical constants for the mission — an estimate of an out-ofspectral band 'leak' in the $\mathrm{CO}_{2}$ narrow channel and the so-called 'twist factor', which accounts for a slight optical rotation of the axis of the FOV mask about the line-of-sight to the horizon [2]. Those two empirical values were the ones that gave a nearly constant ratio of calculated to observed $\mathrm{CO}_{2}$ narrow channel radiances for the altitude range of the middle stratosphere to the middle mesosphere. One-sigma uncertainties for the twist factor are of order $7 \%$, leading to uncertainties in retrieved ozone of the order of several percent. In addition, the $\mathrm{CO}_{2}$ radiances obtained using the bandmodel approximations to the growth of the line-of-sight, path emissivity for the operational algorithm minus those based on more exact, line-byline calculations indicate a slight (-1\% to zero) systematic change in radiance from 40 to $55 \mathrm{~km}$. That approximation alters the retrieved $\mathrm{T}(\mathrm{p})$ by 1 to $2 \mathrm{~K}$ in that region but was difficult to verify based on the comparisons with sets of correlative rocket $\mathrm{T}(\mathrm{p})$ profiles [2].

Climatological distributions of the spectrally-interfering species, CFC-11 and CFC-12, were adjusted backward to 1979, and their effects were accounted for in the forward model. A first-order correction was also made at about $9.6 \mu \mathrm{m}$ based on the UARS HALOE measurements of aerosol extinction at $5.26 \mu \mathrm{m}$ for spring of 1996 and on the SAGE measurements of the magnitude of the aerosol extinction at $1 \mu \mathrm{m}$ in 1979 versus 1996. In this way we accounted for the effects of the weak emissions from a zonal-mean distribution of the near-background, lower stratospheric aerosols of 1979. Finally, a 'two-pass' retrieval was necessary for achieving highly accurate V6 ozone and T(p) profiles; the first-pass was begun using the daily ozone distributions from the V5 dataset, but the second-pass made use of the ozone profile from a first-pass retrieval of V6. The improved T(p) profiles of V6 led to some significant changes for its retrieved ozone, particularly in the mesosphere [2].

b. Identification of spurious features 
A very few ozone profiles had point values exceeding an arbitrary, but liberal, maximum value. As part of a post-processing step, ozone profile segments were screened out if they had values greater than $20 \mathrm{ppmv}$ within the pressure range of $0.2 \mathrm{hPa}$ to $50 \mathrm{hPa}$. Note that the spurious ozone near $0.01 \mathrm{hPa}$ in Fig. 1 is due to contaminating emission from PMC particles; events with PMC-induced errors were not screened from the data.

An effective, upper pressure-altitude limit for the archived $\mathrm{O}_{3}$ profiles was set to account for contaminating radiances from cloud tops. The presence of this cloud-top interference was evaluated based on the fractional vertical gradient for the retrieved ozone mixing ratio, q, below the $45-\mathrm{hPa}$ level for the latitudes equatorward of 30 degrees and below the $100-\mathrm{hPa}$ level for the higher latitudes. Specifically, if there was an increase of $\mathrm{q}$ with decreasing altitude between two adjacent profile points, $\mathrm{n}-1$ to $\mathrm{n}$, (spaced $0.88 \mathrm{~km}$ apart) such that $\mathrm{f}$ in Eq. (1) was greater than 0.25 when $\mathrm{q}(\mathrm{n}-1)$ was greater than $0.5 \mathrm{ppmv}$, then emission from high level clouds was assumed as the cause.

$$
\mathrm{f}=[\mathrm{q}(\mathrm{n})-\mathrm{q}(\mathrm{n}-1)] / \mathrm{q}(\mathrm{n}-1)
$$

Remember that the index $\mathrm{n}$ for the profile points is becoming larger with decreasing $\mathrm{z}$. To be conservative, points at and below the higher altitude level, $\mathrm{n}-1$, were screened out of the archived $\mathrm{O}_{3}$ profiles. This threshold screening represents a first-order detection limit for clouds in the $\mathrm{O}_{3}$ profiles (but see findings from Section 6, too). The effects of smaller amounts of cloud radiance remain in the V6 Level 2 data, but we have not found many instances of clearly spurious ozone due to this remaining bias.

Very similar criteria were used to detect polar stratospheric clouds (PSC) signatures poleward of $45 \mathrm{~N}$ and between 10 and $100 \mathrm{hPa}$. The goal was to eliminate the profile segments with clear, PSC-like signatures, so that one could generate a Level 3 V6 product (Map Archive Tape or MAT) that is essentially free of PSC contamination. Specifically, where the ozone mixing ratios were less than $0.2 \mathrm{ppmv}$ at a pressure level, the profile data points at and below that level were flagged and removed. Those profile occurrences 
were characterized as having excessive attenuation by PSCs along the tangent path and/or an unstable retrieval in the region of the cold, polar winter vortex. A minimum threshold of $0.2 \mathrm{ppmv}$ for ozone is sufficiently close to zero such that a screening was avoided for those regions where real chemical ozone loss may have occurred. It is noted here that this screening threshold would not work well for limb infrared measurements of ozone in the Antarctic winter vortex, where the chemical destruction often leads to nearly zero ozone. When the absolute mixing ratio difference between two adjacent LIMS ozone profile points was greater than $1.7 \mathrm{ppmv}$ and/or when $\mathrm{f}$ in Eq. (1) was greater than 0.7, a PSC indicator was set, and the profile segments below that level were removed. Instances where those criteria were met have been noted in a separate archived data file for each day of the LIMS dataset, and they coincide well with the locations of the spurious "bulls-eyes" that were found in surface maps from a preprocessing analysis of the original V5 MAT ozone fields.

In rare cases a PSC flag was set at locations where PSCs were not expected (region too warm), but where there was pronounced vertical structure in the ozone. Those few cases occurred when the signal from the tangent layer was low. The check for PSCs worked very well for the cold polar vortex region, where a PSC can exist according to the thermodynamic phase criteria for vapor over ice. However, some 'PSC remnants' remain in the profile data, and they become more obvious when the profiles are mapped on a pressure surface and the ozone field is plotted. A screening for values greater than $20 \mathrm{ppmv}$ prior to archival was not conducted from 50 to $100 \mathrm{mb}$, poleward of $30 \mathrm{~S}$ and between $30 \mathrm{~N}$ and $45 \mathrm{~N}$ latitude. About a dozen scans have obviously excess values within those regions, and data users can be alert to them by reading the 'Comments file' that was also archived.

The LIMS instrument was mounted on the Sun-synchronous Nimbus 7 spacecraft with its line-of-sight (LOS) viewing in a direction 33.5 degrees counterclockwise from the negative velocity vector [1]. Its LOS tangent rays pointed in quite different directions, when the same latitude was being viewed from an ascending versus a descending orbital node. This circumstance led to some spurious, ascending minus descending differences in ozone that were hard to correct for, particularly if there are significant horizontal gradients in ozone as discussed in Section 4. A 'two-pass' retrieval and ozone-gradient, correction 
procedure, similar to that used for retrieving temperature, was not implemented for the retrieval of V6

ozone. That step would entail retrieving the daily distributions of ozone, mapping the ozone onto constant pressure surfaces, determining the LOS gradients for the ozone, and then including those gradients in the second pass retrievals of the ozone profiles. If the LIMS instrument had been viewing either in the direction of or opposite to the spacecraft velocity vector, those corrections would have been easier to make, too. However, adding those extra steps would not have accounted for the fact that the observed ozone channel radiances do not emanate from the center of the tangent layer for the middle and lower stratosphere (see Section 4, too) 


\section{Estimates of the quality of the LIMS V6 ozone profiles}

a. Registration effects for the ozone radiances

The quality of the V5 ozone profiles was described in Remsberg et al. [11]. Their estimated uncertainties were rather large but no worse than 15 to $20 \%$ in the upper stratosphere, increasing to $35 \%$ at $30 \mathrm{hPa}$ and

$40 \%$ at $100 \mathrm{hPa}$. Comparisons with SBUV Version 6 and the SAGE I Version 6.0 ozone indicated agreement within their combined uncertainties, respectively, in the mid and upper stratosphere [12]. LIMS V5 had excess ozone in the lower stratosphere at low to middle latitudes, as verified by comparisons with electrochemical concentration cell (ECC) ozonesondes.

Fig. 2 shows the distribution of V6 minus V5 zonal mean differences for LIMS ozone for November 8 , 1978; the improvements for V6 have been judged qualitatively based on Fig. 2 and the validation findings for V5 in Remsberg et al. [11,12]. In particular, the previous excesses of V5 ozone in the middle mesosphere and in the lower stratosphere are reduced or eliminated with V6. V6 ozone is improved for the middle mesosphere due to the changes in the distribution of $\mathrm{T}(\mathrm{p})$ and its better accuracy, as shown in Fig. 3 and as inferred in Remsberg et al. (see Figs. 7 and 8 of [2]). V6 ozone improvements in the lower stratosphere are due to the use of the updated line parameters and weak bands for the ozone forward model, to the accounting for the interfering emission from the aerosols and the CFCs, and to the better characterization of the instrument FOV and its associated effects for the retrieved T(p).

There have been changes in the altitude registrations for the V6 pressure profiles that are due to both a better characterization of the orbital attitude for the LIMS measurements and to the second-pass retrieval of temperature that makes use of the first-pass results for ozone. That two-pass procedure was necessary because ozone near 14 micrometers is a significant contributor to the $\mathrm{LIMS} \mathrm{CO}_{2}$ channel radiances in the middle stratosphere. An emissivity data table that accounts for the overlap of the effects of the ozone lines 
in the $\mathrm{CO}_{2}$ channels was developed and implemented for $\mathrm{V} 6$, in order to account more accurately for the interfering ozone in the forward model of the $\mathrm{CO}_{2}$ channel radiances.

A somewhat extreme example of the effects of those changes is shown in Fig. 2 near $2 \mathrm{hPa}$ and 55N, where the LIMS V6 ozone is larger than the V5 values by as much as $15 \%$. A major part of that change comes from the pressure registrations of the ozone radiance profiles and their associated temperature profiles. Fig. 3 shows that the corresponding, V6 minus V5 T(p) is negative by several degrees from the lower stratosphere to about $2 \mathrm{hPa}$. A persistent, colder temperature for V6 versus V5 over that vertical range causes the V6 profiles of ozone radiance to be registered against pressure-altitudes that are slightly smaller. The effects for the retrieved pressure and ozone profiles are cumulative from the middle stratosphere to the 2-hPa level. Above that level the V6 minus V5 T(p) values are positive, leading to V6 minus V5 biases in ozone that are smaller near the stratopause and into the lower mesosphere.

b. Precision

Table 1, row (a), is the calculated precision for a representative, middle latitude, daytime V6 ozone profile due to the effects of noise and residual offsets, and it ranges from about $1-2 \%$ in the upper stratosphere to $3 \%$ at $0.4 \mathrm{hPa}$, to $18 \%$ at $0.1 \mathrm{hPa}$, and to $11 \%$ at $100 \mathrm{hPa}$. Random percentage uncertainties increase for the mesosphere and for the lower stratosphere because of their low ozone mixing ratios. Fig. 4 shows the observed upper limit estimate of precision for February 1, as obtained from sets of orbital profiles near 30S in the manner of the similar estimates for $\mathrm{T}(\mathrm{p})$ in Remsberg et al. [2]. The standard deviations within those sets agree with the calculated precisions of Table 1 for most levels. Much of the structure within Fig. 4 in the lower stratosphere is likely a result of real and smaller-scale, scan-to-scan variations. There are also random errors due to effects of mechanical jitter for the LOS pointing, and they have been estimated to be of the order of \pm 43 meters (see row (b) and [2]). For situations when the Earth Radiation Budget (ERB) instrument on Nimbus 7 was in its scan mode and causing some additional vibration (or jitter) for the LIMS LOS pointing, row (b) is likely an underestimate of its contributions to a degradation of precision for V6 
ozone. But the ERB scanning operations did not commence until after November 15, 1978, so they are not contributing jitter to the differences in Figs. 2 and 3.

c. Accuracy

Systematic uncertainties are given by the entries that compose the root-sum-square (RSS) error for item (d)

in Table 1. Uncertainties in the calibration, encoder spacing, and the deconvolution of instrument effects from the radiances are largely unchanged from those considered for the V5 ozone, so we have retained those estimates from Remsberg et al. [11] for Table 1. Uncertainties for the ozone line parameters have decreased significantly from those available in 1982, when the emissivity tables for V5 were generated. Line intensities in HITRAN 96 are estimated as known to about 3\%, but are no worse than 5\%. Line half widths are known less well, but are still much better than before. The uncertainty due to the line widths has been estimated in two ways: (1) as having a bias of $10 \%$ and (2) by comparing a forward model, line-byline radiance calculation using the present modified line file (i.e., for the lines with J' less then or equal to 20) versus a line file that was modified for lines out to $J "=30$. Even so, those perturbations to the half widths do not lead to large errors in retrieved ozone.

Uncertainties in the forward radiance model for the ozone channel were estimated by comparing the results using l-b-1 retrievals versus those based on the emissivity tables for the operational V6 algorithm. Those forward model differences are small above the $30-\mathrm{hPa}$ level but increase in the lower stratosphere. Horizontal temperature gradients were obtained from the LIMS V5 MAT and used for the forward model calculations of the ozone channel radiances, so their effects were accounted for, at least to first order.

By far the largest potential systematic effect is due to the estimates of temperature profile bias (see Table 2, row $(\mathrm{g})$ of [2]). Effects on ozone of that $\mathrm{T}(\mathrm{p})$ bias have been scaled from the V5 simulation studies of a uniform $2 \mathrm{~K}$ bias with altitude [2], although biases of that magnitude are unconfirmed and likely upper limits. Such bias effects are most pronounced for ozone in the lower stratosphere, but they are significant in the upper stratosphere and mesosphere, too. There may still be systematic changes in retrieved ozone 
with altitude and season, due to subtle changes in the knowledge of variations in the orbital attitude and, consequently, the registration of the retrieved $\mathrm{T}(\mathrm{p})$ profiles. To assess that possibility, Remsberg et al. [2] showed comparisons of geopotential height versus latitude at a pressure level from LIMS V6 and from the NCEP analyses, and they differed within about $\pm 50 \mathrm{~m}$. However, because there were inconsistencies in the way the heights were calculated for each of those datasets it is unclear whether there is an equivalent bias for the profiles of geometric height that were used in the registration of the LIMS V6 radiance profiles. The effect of a bias in geometric height, if real, would be similar to that for the Table 1 entry, 'residual offset', that contributed to the random error. That bias effect is small for ozone and is not included as a separate entry for accuracy.

There is uncertainty in the estimates of interfering aerosol extinction in the lower stratosphere. The estimated extinction for 1979 at $5.26 \mu \mathrm{m}$ is of order $1 \times 10(-5)$ per $\mathrm{km}$ at $20 \mathrm{hPa}$ and $2.5 \times 10(-5)$ per $\mathrm{km}$ at $50 \mathrm{hPa}--$ equivalent to the near background values of 1999/2000 from the UARS HALOE experiment [2]. Due to a translation with wavelength of those values to the ozone channel and the application of them to the forward model, the LIMS retrieved ozone decreased by $8 \%$ at $30 \mathrm{hPa}$ and by $12 \%$ to $25 \%$ at $50 \mathrm{hPa}$--the larger changes occurring at the lowest latitudes. We estimated that there could be biases of $20 \%$ for the magnitude and wavelength dependence of that extinction, leading to uncertainties in ozone of order 2 to 5\%. Further, since the March/May aerosol distributions were employed for all the LIMS months, this approximate correction may affect the derived seasonal variations of ozone for the lower tropical stratosphere. The effect of aerosol uncertainty on the V6 ozone is given as a separate entry for item (d) of Table 1.

An overall estimate of accuracy for a single V6 ozone profile is given in row (g) of Table 1. It varies from $12-14 \%$ in the upper stratosphere, to $26 \%$ at $50 \mathrm{hPa}$, and $24 \%$ at $0.1 \mathrm{hPa}$. These uncertainties for $\mathrm{V} 6$ are somewhat smaller than reported for V5 by Remsberg et al. [11], but are still significant. Because no compensating effects have been assumed among the various systematic components, these estimates of total accuracy are considered conservative or upper limits. The consistency of those estimates is addressed in Section 4 and their realism is assessed by comparisons with other high quality ozone datasets in Sections 
5 and 6 . In addition, some systematic uncertainties are a function of radiance profile shape and of atmospheric state (i.e., due to the deconvolution of instrument effects and to the vertical temperature gradient and/or bias, respectively). Bias effects may not have the same sign throughout a profile either (e.g., uncertainties of encoder spacing). Therefore, for zonal mean ozone it is reasonable to expect improvements from those accuracy estimates of row $(\mathrm{g})$. Several other possible sources of uncertainty for single profiles have not been included in the overall estimate of accuracy, row (g). For example, the measured IFOV spatial side lobe errors (row (e)) are listed separately, based on the estimates for LIMS V5 in Remsberg et al. [11]. Because those effects are considered upper limits and remain unverified, they were excluded from Table 1. There are several other residual bias effects in the LIMS V6 ozone fields that are difficult to generalize for single profiles. Those effects are presented and discussed in some depth in the next section. 


\title{
4. Residual biases in the LIMS V6 zonal mean ozone distribution
}

\author{
a. Non-LTE effects in the mesosphere
}

The Sun-synchronous, LIMS ascending node (daytime at most latitudes) ozone distributions were checked for consistency against those from the descending node (night at most latitudes). Fig. 5(a) is the monthly average of the daily, ascending minus descending zonal mean LIMS V6 ozone in percent for January. That difference is zero at about the $0.3-\mathrm{hPa}$ level of the lower mesosphere. According to photochemical theory and to the findings from the diurnal, ground-based microwave ozone measurements of Connor et al. [13], the differences should be negative throughout the mesosphere, near zero at about $2 \mathrm{hPa}$, positive by a few percent in the upper stratosphere, and again close to zero in the region from 10 to $100 \mathrm{hPa}$. Obviously, the patterns in Fig. 5(a) were not expected and need to be explained. The differences are also asymmetric between the southern hemisphere $(\mathrm{SH})$ and northern hemisphere $(\mathrm{NH})$.

Previously, it was known that there was an excess of retrieved daytime ozone within the LIMS dataset because of not accounting for the vibrationally-excited emissions from $\mathrm{CO}_{2}$ and $\mathrm{O}_{3}$ in the LIMS forward model [14]. Those so-called, non-LTE radiances affect the retrieved ozone mixing ratio slightly at even lower altitudes, due to the associated, non-linear effects for the retrieval from the optically-thick, strong ozone lines of the upper stratosphere [15]. For example, analogous non-linear, non-LTE processes have been shown to affect the limb infrared retrieval of daytime radiances of water vapor in the 6 to $7 \mu \mathrm{m}$ region even down to the upper stratosphere [16]. Thus, although the LIMS V6 nighttime ozone distributions are nearly correct for the low to mid mesosphere, its daytime distributions are not.

b. Incomplete removal of the effects of temperature tides

There are also systematic effects in the seven months of LIMS ozone due to slightly varying profile biases for its retrieved, day versus night, temperature profiles. For example, ozone is greater for day than night by up to $5-8 \%$ in the mid to upper stratosphere $(10 \mathrm{hPa}$ to $3 \mathrm{hPa}$ ) in Fig. 5(a) at low latitudes. About half of 
that difference is expected from photochemical theory at $3 \mathrm{hPa}$, but much less at $10 \mathrm{hPa}$ [17]. These differences for LIMS have a coherent pattern with altitude and latitude and are traceable to related zonalmean differences in the radiances. This finding for the LIMS V6 ozone is very similar to the A/D differences reported for the V5 data in Remsberg et al. [11], even after corrections had been applied in the V6 algorithm for variations in the orbital attitude. The residual differences in upper stratosphere ozone are explained qualitatively as follows.

Plots of the monthly averages of the daily, day/night differences in ozone have maximum positive values that tend to be most pronounced at the latitude of the overhead Sun. But that relationship does not account for the observed differences with altitude. As discussed below, there are small retrieval differences for its profiles of day/night ozone because of the inability of the LIMS measurements to fully resolve the diurnal temperature tides. Of course, forcing for the diurnal tide varies with latitude, and it has a seasonal variation that is related to the position of the overhead Sun, as well.

Local times for the sun-synchronous LIMS, daytime and nighttime measurements occur at about $1 \mathrm{pm}$ and 11 pm, respectively, across most latitudes. Hitchman and Leovy [18] and Finger et al. [19] reported that the diurnal temperature tide from in situ measurements has a maximum, 'midday minus midnight' difference of nearly $+5 \mathrm{~K}$ near $4 \mathrm{hPa}$ and a zero difference near $1 \mathrm{hPa}$ and $8 \mathrm{hPa}$ at low latitudes, but is somewhat variable with time of year. Fig. 5(b) shows the January average of the daily zonal mean, ascending minus descending differences for $\mathrm{T}(\mathrm{p})$; its maximum difference varies from +3 to $+1.5 \mathrm{~K}$ and is located at 2 to $4 \mathrm{hPa}$, depending on latitude through the tropical regions. Somewhat larger differences were found for February, 1979 (not shown). On the other hand, near-zero differences in T(p) occur from about 0.8 to $1.5 \mathrm{hPa}$ and from 5 to $8 \mathrm{hPa}$. It is also noted that the daily LIMS A/D measurements are separated by about $10 \mathrm{hrs}$ rather than $12 \mathrm{hrs}$, leading to maxima and minima in the vertical that are not spaced at even distances over the profile.

The finite FOV for the LIMS measurement and retrieval dampens the tidal amplitudes within the profile of the observed wide-band $\mathrm{CO}_{2}$ radiances. Because the vertical gradient of the $\mathrm{CO}_{2}$ radiance is fairly steep in 
the upper stratosphere, the finite FOV of the LIMS measurement makes it difficult to fully resolve a smallamplitude, vertical T(p) wave that is located along that gradient [2]. If the wave maximum for the retrieved $\mathrm{T}(\mathrm{p})$ is too low (too cold), the corresponding retrieved ozone will be too large. Similarly about 10 hours later, the retrieved tidal minimum in the $\mathrm{T}(\mathrm{p})$ wave is underestimated (too warm) and leads to retrieved ozone that is too small and not at the same exact altitude as that for the maximum of the tide. The net effect of these retrieved temperature biases is to give day/night differences in ozone that are too large in the upper tropical stratosphere and spread over the finite layer of about 1.5 to $5 \mathrm{hPa}$. The tidal $\mathrm{T}(\mathrm{p})$ and ozone biases are nearer to zero from 0.8 to $1.5 \mathrm{hPa}$ and from 5 to $8 \mathrm{hPa}$ for those same two local times. It is noted that the A/D ratios for LIMS ozone at low latitudes in Fig. 5(a) have a relative minimum at 1-2 $\mathrm{hPa}$, as expected, but not at 5-8 $\mathrm{hPa}$. As mentioned earlier, the diurnal effects of the ozone photochemistry contribute to the effects of the retrieved tidal temperature biases, particularly for the day/night ozone differences near $3 \mathrm{hPa}$. Thus, the fact that the day and night LIMS measurements occur at nearly the same two times for each day is giving rise to a rather complicated, but systematic, pattern with altitude for these zonal mean ozone differences. The small, tidal temperature biases change sign with altitude and are responsible for an oscillatory pattern of error in the tropical ozone profiles of the upper stratosphere to lower mesosphere. The ability to resolve that systematic pattern is an excellent example of the precision of the LIMS radiances plus the inherent sensitivity of the limb infrared sensing technique to small bias errors in temperature for its retrieved ozone.

c. Horizontal gradients in ozone along the tangent path

The foregoing tidal effects do not explain the pronounced, positive, A/D ozone differences of Fig. 5(a) in the middle stratosphere, particularly from $20 \mathrm{~S}$ to $45 \mathrm{~S}$. Furthermore, there are negative differences in the lower stratosphere for the $\mathrm{NH}$ and tropical latitudes, and those differences are characteristic of all the months of the LIMS dataset. Such persistent biases may be related to the viewing directions and the horizontal ozone gradients of the A/D measurements. 
For example, the global distributions for ozone and for temperature for January are nearly uniform in the zonal direction for the $\mathrm{SH}$, making it easier to diagnose the effect of viewing direction on the observed $\mathrm{CO}_{2}$ and ozone radiances and their retrieved results. Remsberg et al. (see Figs. 31 and 32 in [20]) showed that the LIMS ascending node, tangent-layer, LOS viewing direction was nearly parallel to the lines of latitude for SH middle latitudes, i.e., in the zonal direction, where there is almost no variation of ozone along the tangent-layer LOS during summer. Conversely, the descending node LOS was looking nearly perpendicular to the latitude zones of the SH and toward the north. That orientation for the descending node SH observations means that LIMS was looking along the maximum positive gradient for the ozone mixing ratio at the 10-mb level of Fig. 1, or toward the Equator. Note that the viewing direction at $30 \mathrm{~S}$ also has lower ozone toward the satellite side of the tangent layer (see next subsection, too). Thus, it should be apparent that the different viewing geometries plus the gradients along the path for the observed radiances can contribute to an under-estimation of the descending node ozone at about $30 \mathrm{~S}$ and $10 \mathrm{hPa}$ and lead to positive, ascending minus descending differences for the retrieved ozone at those same latitudes in Fig. $5(a)$.

In principle, one can account for the effects of horizontal gradients in the ozone field as part of a 'two-pass' ozone retrieval. Specifically, ozone retrievals can be conducted for all the profiles of a day, the profiles can be mapped onto pressure surfaces, and the ozone gradients in the viewing direction can be determined.

Then, those gradients can be incorporated into the LIMS forward model for calculating the ozone channel radiances, as part of the second-pass retrieval step for obtaining final ozone profiles. Such an approach was taken to account for the effects of the horizontal temperature gradients. Because the effects of ozone gradients were smaller they were not included.

d. The asymmetric weighting of ozone radiance across the tangent layer

The bulk of the radiance in the middle stratosphere comes from the optically-thick bands of the LIMS ozone channel and is weighted toward the satellite side of the tangent-layer, even though the retrieved ozone is assigned to the center of the tangent layer for the LOS mass-path integrations. To illustrate, Fig. 6 
shows the amount of horizontal asymmetry along a typical limb-path for the ozone measurements at four selected altitudes. The contributions to the radiance are defined from those weighting functions, $\mathrm{D} \tau / \mathrm{d} s$, where $\tau$ is the broad-band transmission for the LIMS ozone channel and $s$ is the path length, as adapted from Gordley and Russell [4]. The radiances at $50 \mathrm{~km}$ are derived from the strong, but not quite opticallythick, ozone lines and tend to maximize at the center of the tangent layer. The weightings at $40 \mathrm{~km}$ and 30 $\mathrm{km}$ are derived using mostly those same lines, but they have grown optically-thicker. Their horizontal weighting functions are non-symmetric and peak toward the satellite side of the nominal 300-km long tangent layer, as indicated by the negative values for the distances from the center of the tangent layer of the abscissa of Fig. 6. The radiances are not representative of the exact conditions for ozone at the center of the tangent layer in that case; that situation can be aggravated where there are horizontal gradients in its ozone field, too. Note also that the magnitudes of the weighting functions in Fig. 6 are even larger at 30 $\mathrm{km}$, as more ozone molecules are encountered.

Most of the change in the signal from the tangent layer at $20 \mathrm{~km}$ comes from the pressure-broadened lines of the weaker ozone bands. Yet, the weighting along the LOS is greatest from 'far in front of the tangent layer' (-500 km distance), which really means that the bulk of the radiance is coming from above the tangent layer (see also the vertical weighting functions of Fig. 2 in Remsberg et al. [11]). This circumstance is not a problem for retrievals in the lower stratosphere with the 'onion-peeling' approach of the LIMS algorithm, as long as the biases for the retrieved ozone remain small at the altitudes above the tangent layer. However, there is a suspected bias of about $-10 \%$ in the descending node ozone of Fig. 5(a) at $30 \mathrm{~S}$ and $10 \mathrm{mb}$. That effect persists for lower altitudes and leads to the larger, positive A/D differences at the $\mathrm{SH}$ middle latitudes.

The ascending and the descending tangent paths for the NH are more nearly opposite and also perpendicular to the lines of latitude. On the ascending node the view was from the north and toward the Equator, or toward higher ozone at $10 \mathrm{mb}$ (Fig. 1). Also the observed radiances for that $\mathrm{NH}$ node were weighted toward the lower ozone mixing ratios of the front side of its tangent layer. Because no adjustments were employed to correct for those two biases, their effects have tended to compensate. On the 
other hand, the view for the descending node observations of the $\mathrm{NH}$ was from the south, down the ozone gradient, and weighted toward the higher ozone mixing ratios of the front side of the tangent layer. The same two bias effects are positive and tend to reinforce for the descending node. As a result, the positive, ascending minus descending ozone values at $10 \mathrm{mb}$ in Fig. 5(a) have decreased to near zero at $20 \mathrm{mb}$ for the tropical and NH latitudes. Then, the differences become negative in the lower stratosphere. Further, it can be seen that there is a reversal of the meridional gradient of the 5 ppmv ozone contour near $45 \mathrm{~N}$ and 30 $\mathrm{mb}$ in Fig. 1. The variation of that gradient is very similar to that of the contour of zero difference for the same latitude region of Fig. 5(a) - an indicator of a sensitivity of the LIMS retrieved ozone to the gradients of its fields.

Ozone differences close to the tropical tropopause in Fig. 5(a) are primarily due to effects from residual cloud-top radiances plus the different viewing directions of the A/D orbital segments. These residual errors are systematic, often large, and not so repetitive. They have not been included in Table 1 because they are difficult to quantify or to know in advance. Such effects are a reason for follow-on, limb-infrared instruments to include additional ozone measurement channels located in the more optically thin and/or weaker bands of ozone. Even so, because the LIMS ozone channel covered a large wavelength range (having its $5 \%$ filter transmission points at 925 and $1136 \mathrm{~cm}^{-1}$ ), much of its change in transmission below the ozone peak is due to the pressure-broadened lines of the weaker and optically-thinner, overtone and combination bands [5]. Thus, the LIMS experiment should have been capable of achieving good quality ozone results even in the lowermost stratosphere because the line parameters of those weak bands are now reasonably accurate and because the horizontal gradients for the large-scale, ozone fields are small [21]. The realization of that prospect is evaluated to first order in Section 6 based on several comparisons of the LIMS V6 and correlative balloon ozone profiles.

To summarize the residual biases that we have found, the hemispheric differences for the LOS viewing directions together with their tangent-layer weightings are tending to give small, but persistent, A/D ozone difference patterns for all seven LIMS months. Those patterns are consistent with the zonal mean character of their monthly stratospheric ozone distributions, which are modified only slightly by the action of the 
zonal waves of the late fall and winter hemispheres. One should not conclude that these subtle, LIMS-

retrieved ozone differences are entirely real, and it is an important reason for conducting comparisons with some high quality correlative measurements (Sections 5 and 6). Yet, it is quite impractical to develop more accurate corrections for the non-linear effects of the asymmetric weightings of the radiances within the tangent layer. Thus, those effects represent a minor limitation for achieving better quality ozone profiles with a single ozone channel having the spectral bandwidth characteristics of the LIMS instrument. It is recommended that one make use of both the ascending and descending node LIMS ozone profiles for scientific study, in order to reduce the impact of these residual biases. By combining the profiles from both nodes within a latitude zone, one can also take advantage of their improved sampling for resolving the effects of the smaller-amplitude and intermediate-scale zonal waves. 


\section{Comparisons with the SBUV Version 8 ozone dataset}

Correlative measurements of ozone were sparse for the upper stratosphere and mesosphere during the LIMS timeframe, being limited to a few rocket soundings and some low resolution, ground-based Umkehr measurements from several stations at NH middle latitudes [11]. However, the SBUV instrument provided near-global ozone data from the same Nimbus 7 satellite. The SBUV dataset is based on an optimal estimation algorithm and contains daytime profiles of moderate vertical resolution. Its retrieved profiles are also reasonably valid for the lower stratosphere (down to the 64-hPa level) because its a priori estimates are based to some extent on profile shape versus latitude and month from the higher-resolution SAGE II and ozonesonde datasets [22]. The recently-released, SBUV Version 8 (V8) ozone algorithm employs sets of monthly a priori profiles and an error covariance matrix that are the same from year to year although not necessarily optimal for a given day of a month or for a given year [23]. Still, SBUV V8 is considered a standard for comparison purposes for stratospheric ozone. Therefore, the LIMS zonal-mean ozone results have been compared with the SBUV V8 data for two specific days-November 8, 1978 and May 6, 1979. Those dates were chosen because they are within a day of two of special balloon comparison campaigns for the LIMS experiment out of Palestine, Texas. Comparisons are also shown for a third day, March 15, 1979, that is representative of NH spring equinox conditions.

Bhartia et al. [23] describes the SBUV V8 algorithm that generates ozone profile information in terms of 13 layers, each having a thickness of $3.2 \mathrm{~km}$ and with their ozone in terms of Dobson units (DU). The layer designations are in terms of their bottom pressures in fractions of an atmosphere that we converted to units of $\mathrm{hPa}$ by multiplying by $1013.25 \mathrm{hPa}$. Vertical resolution for these SBUV profiles is estimated to be as good as $6 \mathrm{~km}$ in the upper stratosphere, broadening to $8 \mathrm{~km}$ or more above the $1-\mathrm{hPa}$ and below the $10-\mathrm{hPa}$ levels. The SBUV results for layers lower than the $30-\mathrm{hPa}$ and higher than the $1-\mathrm{hPa}$ levels are constrained more by the shape of their a priori profiles. Ahn et al. [24] showed that the SBUV V8 ozone compares well with large sets of profiles from standard correlative measurements, including those by ground-based microwave and lidar and by balloon-borne ozonesonde techniques. They found that the differences were within $\pm 10 \%$ from $30 \mathrm{hPa}$ to $1 \mathrm{hPa}$, averaging to within about $5 \%$. 
In the present study the daily SBUV profiles were collected into 2-degree wide latitude bins and then averaged to a zonal mean after the profiles. The data were not screened of the lower quality profiles at very high solar zenith angles. The LIMS V6 ozone has a vertical resolution of order $3.7 \mathrm{~km}$ and is compatible with the resolution of its retrieved T(p) [2]. However, the LIMS ozone profiles were not convolved with the averaging kernels of the SBUV experiment to have results of the same exact vertical resolution. Instead, the LIMS ascending node (daytime) profiles were merely integrated to give ozone amounts for the same 3.2-km layer increments as SBUV, and then they were binned within 2-degree latitude zones, too. If there were less than 6 LIMS profiles (out of about 20) in a latitude bin, the zonal averages were assumed to be non-representative and were not used. We did not make comparisons for the highest SBUV layer (above $0.405 \mathrm{hPa}$ ) or for its lowest layer that extends from the surface to $63.9 \mathrm{hPa}$.

Results of the LIMS/SBUV zonal-mean comparisons for March 15, 1979, are shown for four selected layers (1.6-1.0 hPa, 4.1-2.5 hPa, 10.1-6.4 hPa, and 40.5-25.4 hPa) in Fig. 7 (a-d). There is very good agreement in the relative variation of ozone with latitude for panels (a-c), where the SBUV results have both good precision and accuracy. The increase in SBUV ozone toward higher NH latitudes (and zenith angles) at 1.6-1.0 hPa is followed well by the LIMS ozone. The effect of the semi-annual oscillation (SAO) in ozone is apparent at low latitudes of both datasets for the layer, 4.1-2.5 hPa, and for the next lower layer (not shown), in response to SAO variations in the trace gases that contribute to ozone loss [25]. However, LIMS ozone is higher than SBUV ozone by about $10 \%$ across most latitudes for the layer, 4.1$2.5 \mathrm{hPa}$, and we address that difference later. Agreement is nearly exact for the two datasets at 10.1-6.4 $\mathrm{hPa}$, panel (c). The only exception is poleward of $70 \mathrm{~N}$, where SBUV ozone begins to increase, while LIMS ozone levels off and then decreases. Those differences are characteristic of the reduced accuracy for the SBUV retrieval at high zenith angles. For the layer 40.5-25.4 hPa of panel (d) the LIMS ozone also agrees well with SBUV, and the NH springtime accumulation of ozone is apparent at the higher latitudes. LIMS is lower than SBUV by up to $15 \%$ in the tropics for this layer. 
Percentage zonal mean differences (LIMS minus SBUV divided by SBUV) are given in Fig. 8(a) for November 8, 1978, in Fig. 8(b) for March 15, 1979, and in Fig. 8(c) for May 6, 1979. In general, there is agreement within the combined accuracies for the two datasets for the stratosphere from 64 to $1 \mathrm{hPa}$. Further, the agreement in Fig. 8 (a) at $1.5 \mathrm{hPa}$ and $55 \mathrm{~N}$ is of order $6 \%$, indicating that the rather large increase of $15 \%$ for that same region of Fig. 2 was a definite improvement for the LIMS V6 versus V5 ozone.

There are patterns in the differences from the three panels of Fig. 8 that are of interest, and they are grouped and discussed according to three separate pressure-altitude ranges. First, there is an excess of LIMS versus SBUV ozone at 1.0 to $0.6 \mathrm{hPa}$. That excess is greatest for May. Near $0.6 \mathrm{hPa}$ it is affected by the lack of a correction for the non-LTE radiances of the LIMS $\mathrm{CO}_{2}$ and ozone bands in the LIMS ozone channel. There are also likely biases in the SBUV results at these altitudes because of the constraints toward the a priori profile in its algorithm. In fact, Ahn et al. showed that the ground-based microwave ozone is also larger than that from SBUV V8 by about $10 \%$ at about $0.5 \mathrm{hPa}$ (see Fig. 3 in [24]). An additional $2.5 \%$ of the excess in LIMS versus SBUV ozone at $1 \mathrm{hPa}$ is explained by the fact that the LIMS algorithm accounts for a gravitational acceleration ' $\mathrm{g}$ ' that decreases with height, whereas the SBUV algorithm does not [22]. That effect becomes slightly larger at higher altitudes due to the hydrostatic calculations for their respective pressure profiles and their associated ozone amounts.

Secondly, there is a horizontal, banded pattern for the LIMS/SBUV differences in Fig. 8 that is more apparent for March 15 and, especially, May 6, as compared with November 8. Those differences are a minimum at 1-2 $\mathrm{hPa}$ and a maximum at 3-4 $\mathrm{hPa}$. Could the bias in LIMS ozone for a particular layer be an indirect, yet, sensitive indicator of a LIMS temperature bias? According to Table 1, a positive bias of only 1 to $2 \mathrm{~K}$ at $1 \mathrm{hPa}$ can lead to a negative bias of 6 to $12 \%$ in ozone at the same level (the region of the minimum differences in Fig. 8) and can offset some of the excess in the retrieved LIMS ozone due to the daytime non-LTE effects from above. 
Figs. 9(a,b) show the temperature distributions for November 8 and May 6, respectively. In particular, there appears to be good correspondence for May at tropical and NH latitudes between the pattern of the minimum in the ozone difference at 1-2 hPa in Fig. 8(c) and the occurrence of the steep vertical temperature gradient for the same pressure range in Fig. 9(b). Because of the inability of the LIMS measurement and retrieval to fully resolve the amplitude of the temperature tide in the tropical upper stratosphere, it is reasonable to suspect that the steep gradient in NH T(p) has been underestimated. There have been T(p) comparisons for LIMS V5 with NH middle-latitude, rocket-borne Datasondes and falling spheres [26] and comparisons between the daily V6 and V5 zonal mean temperatures in Remsberg et al. [2] and at the LIMS Website. The combination of all those results indicates that the LIMS V6 T(p) may be warm by several degrees from 1 to $2 \mathrm{hPa}$, but about right from 3 to $5 \mathrm{hPa}$. That conclusion is tentative, however, because the accuracies for $\mathrm{T}(\mathrm{p})$ from the Datasonde and from the sphere are really not known to better than about $2 \mathrm{~K}[27,28]$. A slightly warm $\mathrm{T}(\mathrm{p})$ at 1-2 $\mathrm{hPa}$ will lead to a small deficit in LIMSretrieved ozone for the same layer, followed by a slight, compensating excess of ozone in the layer from 2$4 \mathrm{hPa}$. That compensation is a consequence of the need to match the calculated and the observed ozone channel radiances as part of the LIMS onion-peeling retrieval scheme. On the other hand, there is not a comparable pattern of bias in the retrieved ozone for November in the $\mathrm{SH}$, where the temperature gradients are also steep in the upper stratosphere (refer to Figs. 9(a) and then 8(a)).

There are also small biases for the SBUV ozone of the upper stratosphere related to its forward model, vertical resolution, and assumed a priori profiles. For example, one assumption for the earlier SBUV V6 algorithm was that the ratio of the ozone scale height to the atmospheric scale height is a constant for the ozone column above a given pressure level in the upper stratosphere $[22,29]$. Certainly, the atmospheric scale height is becoming larger from about 10 to $1 \mathrm{hPa}$ as $\mathrm{T}(\mathrm{p})$ increases. The scale height for ozone also varies in the upper stratosphere because that is where the chemical equilibrium for ozone is dominated by the Chapman mechanism with its highly temperature-dependent loss reaction, $\mathrm{O}+\mathrm{O}_{3} \rightarrow 2 \mathrm{O}_{2}$. That loss process leads to a decreasing ozone scale height toward the stratopause. Thus, if both of these scale heights are allowed to vary with altitude, they would lead to increases in the overhead partial column ozone. To the extent that those scale heights remain constant for the a priori profiles of the SBUV V8 algorithm, its 
retrieved ozone may be underestimated in that region and contribute to the enhancement in the

LIMS/SBUV ozone differences at 3 to $4 \mathrm{hPa}$ of Fig. 8. Bhartia et al. conducted a simulation for the SBUV algorithm that indicated a damped and somewhat broader retrieved response to an 8-km-wide impulse for the ozone profile (see Fig. 7 in [22]). With that in mind it is noted that the character of their degraded responses and of the SBUV minus microwave ozone profiles in Ahn et al. (see their Fig. 3, [24]) have a vertically-oscillatory signature of similar amplitude and wavelength to that of Fig. 8.

For the same reasons it is also likely that the true seasonal amplitudes in layer ozone of the upper stratosphere are being constrained more by the SBUV than by the LIMS algorithm. In fact, there are indications that the seasonal ozone amplitudes are underestimated by SBUV, based on a time series comparison of SBUV Version 6 versus SAGE II Version 5.9 sunset ozone for the 5-km thick Umkehr layer 8 (2-4 hPa), even after the SAGE II data had been integrated over that layer depth [30].

Finally, patterns for the ozone differences from about 7-63 hPa in Fig. 8 are asymmetric between the SH and the $\mathrm{NH}$, and that character is similar for all three days. Recall that the LIMS ozone radiances are skewed toward the satellite side of the tangent layer and that condition was not accounted for in calculations along the view path within the forward model of its algorithm. It was also noted earlier that the LIMS ascending (daytime) node measurements were obtained looking nearly along the lines of latitude at SH middle latitudes - in the zonal direction where horizontal gradients are normally small. Conversely, the ascending LIMS view for the NH stratosphere was from the north and more nearly along the horizontal gradient of ozone. One exception among the three plots of Fig. 8 is their differences poleward of about $50 \mathrm{~N}$, particularly for November 8 . The LIMS ascending LOS gradients are fairly weak at middle to high latitudes of the NH middle to upper stratosphere for March and May, but much stronger in November. Because ozone decreases smoothly toward the NH polar vortex in November and because the bulk of the radiance is really coming from the satellite-side of the tangent layer, the LIMS algorithm underestimates the true ozone in that region for November. Since SBUV is a nadir viewing measurement, it has no equivalent problem for centering the source of its backscattered measurements along the orbital tracks. However, there may be biases in the SH versus the NH a priori profiles for SBUV that have amplified the 
differences in Fig. 8 for the lower stratosphere. Still, it is concluded that a low bias for the LIMS

ascending-node ozone in this region is the primary reason for the more negative LIMS/SBUV differences at the higher latitudes of the $\mathrm{NH}$ on November 8 . 


\section{Comparisons with ozone profiles from ECC sondes}

Remsberg et al. [11] showed that the LIMS V5 ozone was generally too large in the lower stratosphere compared with data from several types of balloon-borne ozone instruments. Ozone profile comparisons with data from the well-characterized ECC sonde technique represent a standard for assessing the quality of satellite ozone measurements in the lower stratosphere, even today. It is also well-known that the effects of spatial smoothing for a limb-viewing satellite measurement technique can affect the quality of a comparison with an individual balloon profile. During the time period of the LIMS measurements there was not an abundance of ECC balloon soundings that coincided with the satellite overpasses and the track for the LIMS view, so we have not undertaken a comprehensive comparison study for ozone quality in the lower stratosphere. Instead, we show several examples that ought to be representative for the NH middle latitudes.

Fig. 10(a) contains an ECC ozonesonde profile and an average of 3 ascending and 3 descending LIMS ozone profiles that were located within 2 degrees of latitude and 15 degrees of longitude of the ECC measurement from Hohenpeissenberg, Germany (48N, 11E), for March 14, 1979, as obtained from the World Ozone Data Center (WODC). The respective ozone profiles are plotted in terms of ozone partial pressure versus pressure--the fundamental quantity reported for the ozonesonde, in order to focus on the quality of the LIMS results in the lower stratosphere. The agreement is within about $10 \%$ above the $80-\mathrm{hPa}$ level. The corresponding T(p) comparison in Fig. 10(b) is within $3 \mathrm{~K}$ above the $100-\mathrm{hPa}$ level. The LIMS ozone profile in Fig. 10(a) does not extend below about the 80 -hPa level because of the criterion that we used to detect the interfering presence of high clouds, as defined in terms of the vertical gradient of the ozone mixing ratio from Eq. (1). However, there is a clear indication of laminar ozone near $120 \mathrm{hPa}$ in the ECC sonde profile that would also result in the lower part of its profile being flagged and discarded had we applied the LIMS criterion for clouds to the vertical ozone gradient from the ECC measurement.

Fig. 11 is another co-located ozone comparison, but for Wallops Island, Virginia (38N, 285E), on March 11, 1979. In this case the ECC profile extends no higher than about the 35-hPa level. Still, the four 
separate nearby LIMS profiles agree well with it, except that they show no indication of the small-scale vertical structure of the sonde profile at $70 \mathrm{hPa}$. That deficiency is due, in part, to the lower vertical and horizontal resolutions of the LIMS result, but may also be due to a lack of co-location with the sonde profile. The LIMS profiles cutoff near $100 \mathrm{hPa}$, again in response to the large secondary maximum in the ozone that is indicated in the sonde profile from about 100 to $200 \mathrm{hPa}$. It should be clear that the LIMS V6 screening algorithm was indicating the presence of clouds in this instance, when in fact there likely were none. In hindsight the check for cloud signatures poleward of 30 degrees latitude should have been initiated nearer to $200 \mathrm{hPa}$, rather than at $100 \mathrm{hPa}$, in the LIMS V6 operational software. It also means that the LIMS V6 zonal-mean ozone is not so representative of the true zonal variations of atmospheric ozone below the 100-hPa level.

Although the LIMS V6 profiles in these two cases tend to smooth through the vertical layers of the ECC ozone profiles, one can see that the LIMS profiles are registered accurately with pressure altitude and that there is no clear evidence of a persistent high or low bias in the lower stratosphere. The results from Figs. 10 and 11 indicate that the typical changes for ozone from LIMS V5 to V6 in Fig. 2 are a definite improvement for its accuracy in the lower stratosphere. The results also suggest that single profile accuracy is close to that in row (h) of Table 1 at 50 and $100 \mathrm{hPa}$. Thus, it is concluded that the retrieved LIMS V6 ozone has benefited from the algorithm improvements for the removal of temperature and instrument effects (e.g., FOV effects) and for the updates to the ozone line parameters within its ozone channel filter. 


\section{Initial scientific findings and further prospects}

Fig. 12 is a plot of NH LIMS V6 ozone at $10 \mathrm{hPa}$ for January 27, 1979, for comparison with the similar plot based on the V5 data in Leovy et al. (see Fig. 3(b) in [31]). The V6 ozone profile data were mapped zonally to within their precision and analyzed for their zonal wavenumbers for each 2 degrees of latitude in the manner of Remsberg et al. [32]. Grid point values were generated based on the coefficients for the zonal waves, and then Fig. 12 was plotted after applying an additional 1-2-1 grid-point smoothing. One way to assess the precision and relative accuracy of the LIMS V6 profiles is to observe the degree of continuity in the daily, mapped ozone fields across adjacent latitudes. Although there is a good bit of structure in the field, there is also good continuity for the large-scale features of the ozone distribution. The subtropical barrier or edge of the so-called 'surf-zone' is clearly present in the subtropics of the Pacific region. There is an even tighter meridional gradient over the North Atlantic that is separating the subtropical ozone and vortex ozone with no apparent surf zone in between. The greater detail that is possible with the LIMS V6 dataset is due mostly to the fact that retrievals were performed using all the profiles along the orbits, rather than every $6^{\text {th }}$ profile, and the mapping was conducted at every two degrees of latitude rather than every four. The improved sampling within a profile has also reduced the smoothing effects of the vertical interpolation of the data points to a given pressure level, prior to the mapping.

The LIMS V6 ozone is more suitable for comparisons with other satellite datasets because of the updates for the spectroscopic line parameters that were used for its retrieval. These updates are important for comparison studies of chemical ozone loss during the two decades after 1979 when the total chlorine was increasing. For example, polar stratospheric clouds were present for both the NH winters of 1978/79 and 1999/2000, the latter period when the NASA SOLVE polar aircraft campaign was conducted. It ought to be instructive to compare the extent of the chemical ozone loss for those two winters. Because retrievals have been conducted for all of the radiance scans for the generation of the LIMS V6 dataset and because its temperature profiles are accurate even in the polar winter stratosphere, the LIMS V6 ozone contains nearsynoptic detail and an accuracy that exceeds what has been available up until now for that atmospheric region. From the LIMS V6 profiles of geopotential height one can also prepare its daily maps on a pressure 
or potential temperature surface and calculate the large-scale wind and potential vorticity fields. It should then be possible to re-assess the effects of transport on ozone and its associated chemical species in the region of the polar vortex. The LIMS V6 dataset can also be used for more detailed and quantitative studies of atmospheric chemical and dynamical processes throughout the stratosphere.

Natarajan et al. [3] re-determined the model ozone deficit for the upper stratosphere by comparison with LIMS V6 ozone for January. They found model deficits of no more than $15 \%$, which is within the combined uncertainties of the data and the kinetic mechanisms for their diurnal model. Their model ozone deficits were also no less than $12 \%$ in the lower mesosphere, at least when compared with the V6 nighttime ozone.

Siskind et al. [33] reported on seasonal data/model ratios for upper stratospheric ozone at $35 \mathrm{~N}$ and $40 \mathrm{~S}$, based on their model comparisons with the LIMS V5 ozone dataset. They found model deficits at 2 to 3 hPa that were largest for late spring and summer. Conversely, Chandra et al. [34] conducted model comparisons using SBUV V6 ozone and an NMC seasonal temperature climatology and found model deficits that were somewhat larger for winter. That discrepancy was puzzling and caused doubts about the quality of the LIMS dataset as a diagnostic of seasonal predictions with models. However, it was found that the seasonal variations of the data/model ratios of Siskind et al. [33] were reduced considerably after replacing the V5 with the V6 LIMS ozone. In fact, their monthly ratios at $2 \mathrm{hPa}$ and $35 \mathrm{~N}$, but based on the observed V6 ozone, now compare very favorably with the nearly-constant, model/data ratio of 1.25 that they found for ground-based microwave measurements of ozone at Table Mountain, California (34N).

We conducted model/data comparisons of upper stratospheric ozone for all 7 of the LIMS months for this paper and in the manner of Natarajan et al. [3], who made use of the LIMS V6 values of temperature, $\mathrm{NO}_{\mathrm{x}}$, and water vapor, as well as ozone. We then checked for model/data differences with season. The monthly, model minus LIMS V6, ozone results for 30N are shown in Fig. 13. There is a clear model deficit of 12 to $16 \%$ near $1.5-2 \mathrm{hPa}$, decreasing to about $5 \%$ at $0.5 \mathrm{hPa}$ and at $5 \mathrm{hPa}$. The deficit at $2 \mathrm{hPa}$ is slightly larger for springtime, although the apparent seasonal variation of only $5 \%$ may not be significant. The model 
deficit in Fig. 13 has the same phase, but is smaller than that of Siskind et al. [33] based on the LIMS V5 data.

Fig. 14 is a plot similar to Fig. 13, but for 40S. At this latitude there is a nearly uniform model deficit versus the V6 ozone of up to $12 \%$ across all 7 months, as contrasted with that found by Siskind et al. [33]. Furthermore, at $5 \mathrm{hPa}$ the ozone is not exactly in chemical equilibrium for wintertime, as assumed for the model calculations. Thus, at the higher latitudes there is a net poleward transport of ozone during winter that is not accounted for in the model comparisons. There are also indications from Ahn et al. (see Fig. 2 in [24]) that the seasonal variation of SBUV V8 ozone in the upper stratosphere has decreased at 45S from that for SBUV V6 of Chandra et al. [34]. It is concluded then that the most recent versions of these LIMS and SBUV datasets are giving seasonal results for upper stratospheric ozone that are more in line with those from the photochemical models. 


\section{Summary}

The LIMS V6 ozone is improved over that from the V5 dataset due to: (1) a more accurate accounting for instrument and satellite orbital effects in the radiances, (2) better spectroscopic line parameters for ozone, (3) more accurate and compatible temperature profiles, (4) better spatial sampling and retrievals of all the scans, and (5) a better accounting for interfering species in the lower stratosphere, at least outside the tropics. The profiles also extend higher or to near the $0.01-\mathrm{hPa}$ level. These improvements are reflected in the smaller estimates of data uncertainty in rows $(\mathrm{g})$ and $(\mathrm{h})$ of Table 1 . In particular, the V6 T(p) is more accurate in the mesosphere, leading to the improvements for both its daytime and nighttime ozone. The LIMS V6 temperatures may be too warm by up to $2 \mathrm{~K}$ at 1 and $2 \mathrm{hPa}$ for both day and night, due to an inability to completely resolve its steep vertical gradient in that region. There is no evidence of a persistent temperature bias in the rest of the stratosphere, except for small biases in the presence of the tides of the tropical upper stratosphere. Therefore, it is concluded that the most appropriate estimate for the total bias in the LIMS V6 zonal mean ozone is from row (h) of Table 1. That accuracy estimate is \pm 9 to $\pm 7 \%$ from 50 to $3 \mathrm{hPa}$, respectively.

There is evidence of some minor systematic biases in the LIMS V6 ozone. Non-LTE effects are present for V6 daytime ozone in the mesosphere, and its day/night differences are larger than predicted from diurnal ozone photochemistry; the nighttime ozone is affected less by non-LTE processes. A day minus night difference of order $5 \%$ is present for V6 ozone in the upper stratosphere at low latitudes. That difference is larger than expected and is due to the $\mathrm{LIMS} \mathrm{CO}_{2}$ channel measurement and retrieval not being able to fully resolve the amplitude of the diurnal temperature tide. We are therefore unable to completely account for its effects in the ozone channel radiances. There are also some unrealistic day/night ozone differences in the middle and lower stratosphere that are a consequence of the different LOS viewing directions for the A/D orbital segments. The horizontal weighting for the measured ozone radiance is not at the center of the tangent layer either, and the retrieved results are affected slightly by horizontal gradients in the ozone fields themselves. It is recommended that scientific studies of LIMS ozone in the stratosphere be based on the combined ascending and descending node data. 
The LIMS V6 ozone distributions were compared with those from SBUV V8 for several selected days. SBUV ozone has been shown to be of good quality throughout most of the stratosphere and is used as a standard for comparison. The two datasets agree within their combined accuracies, even in the lower stratosphere. However, there are apparent patterns in the plots of their zonal average differences that are traceable to the non-LTE effects for LIMS in the daytime ozone in the mesosphere and to the effects of the LOS viewing and ozone gradients in the middle and lower stratosphere. The causes of the minor differences that remain for upper stratosphere ozone are not understood as well at this time. Those differences may be related to small biases in temperature for LIMS and/or to effects from the $a$ priori profiles and the optimal estimation approach for SBUV. Comparisons with ECC ozonesonde profiles at NH middle latitudes are indicating that the LIMS V6 ozone has good accuracy down to the 100-hPa level. This finding means that the LIMS technique and its V6 ozone are suitable for science studies, even at that level - a definite improvement from the poorer accuracy of the LIMS V5 ozone in the lower stratosphere.

The LIMS V6 retrievals were performed for all of the measured radiance scans, providing for improved sampling of the relative variations of ozone. Estimates of ozone precision from the data themselves are better than $3 \%$ from 1 to $30 \mathrm{hPa}$. As a result, there is better continuity and detail for the variations of ozone on a pressure surface with the V6 ozone dataset. It is well-known that the trace chemicals in the stratosphere and its ozone have changed from 1978/79 to the present day. Because the spectroscopic line parameters for ozone have been updated to those in HITRAN 96 and their halfwidths then modified for the processing of LIMS V6, it is now possible to interpret differences in the ozone loss during 1978/79 versus that for similar winters during the more recent periods of the measurements from the UARS, ENVISAT, EOS AURA, and the several solar occultation satellite experiments. The improved estimates of the orbital attitude for the profiles of the LIMS V6 dataset have also led to comparisons of LIMS versus model ozone that show little to no seasonal variation for their differences in the upper stratosphere.

One can view the LIMS V6 data at its Website, http://lims.gats-inc.com. Diagnostic zonal mean and surface plots are available for both V5 and V6 for each of the days when LIMS was operating. The V6 
data were certified by an inspection of their daily difference plots; that assessment is available in the 'Data

Quality Comments' file on the Website. The V6 Level 2 dataset is available via ftp download and on CD

ROM media on request from the NASA Goddard/DAAC. The profile format and several example scans can also be obtained from the DAAC. 


\section{Acknowledgments}

The research leading to the improvement and generation of the LIMS V6 Level 2 ozone dataset was conducted under the direction of EER with funds from several NASA NRA proposals and consistent support from Jack Kaye, Joe McNeal, and Mike Kurylo during the 1990s. The processing of the LIMS dataset to V6 was conducted by GATS, Inc., under a subcontract from SAIC. The algorithm for the high quality LIMS V6 T(p) profiles was developed by GATS, Inc., and those results are critical to achieving the precise and accurate LIMS V6 ozone profiles. That effort by GATS, Inc., was partially funded by the Integrated Program Office (IPO) of NOAA through contracts to Orbital Sciences Corp. and LockheedMartin Corp. for technical studies prior to the selection of the NPOESS Ozone Monitoring and Profiling Suite (OMPS). The validation of the LIMS V6 ozone product was achieved by comparisons with the SBUV V8 ozone with support from NASA's TIMED/SABER Project and Richard Goldberg of NASA

Goddard in preparation for a similar assessment of the SABER 9.6 $\mu \mathrm{m}$ ozone dataset. The mapping of the LIMS V6 ozone was supported by funds from a NASA TIMED Guest Investigator Proposal (PI-Rolando Garcia). The ECC ozonesonde data were provided courtesy of Vince Brackett of SAIC. EER appreciates the discussions that he has had with Rich McPeters, P. K. Bhartia, and Matt Deland about the quality of the SBUV V8 dataset, particularly for its early NIMBUS 7 period of 1978/79. 


\section{References}

[1] Gille JC, Russell III JM. The limb infrared monitor of the stratosphere (LIMS): experiment description, performance and results. J Geophys Res 1984;89:5125-40.

[2] Remsberg EE, Gordley LL, Marshall BT, Thompson RE, Bruton J, Bhatt P, Harvey VL, Lingenfelser

G, and Natarajan M. The Nimbus 7 LIMS version 6 radiance conditioning and temperature retrieval methods and results. JQSRT 2004;86:395-424.

[3] Natarajan M, Remsberg EE, and Gordley LL. Ozone budget in the upper stratosphere: model studies using the reprocessed LIMS and the HALOE datasets. Geophys Res. Lett 2002;29:56-1 to 56-4.

[4] Gordley LL, and Russell III JM. Rapid inversion of limb radiance data using an emissivity growth approximation. Appl Opt 1981;20:807-13.

[5] Smith MAH, and Gordley LL. Sensitivity of ozone retrievals in limb-viewing experiments to errors in line-width parameters. JQSRT 1983;29:413-18.

[6] Rothman LS, et al. The HITRAN molecular spectroscopic database and HAWKS (HITRAN Atmospheric WorKStation): 1996 edition. JQSRT 1998;60:665-710.

[7] Smith MAH, Devi VM, Benner DC, and Rinsland CP. Temperature dependence of air-broadening and shift coefficients of $\mathrm{O}_{3}$ lines in the $v_{1}$ band. J Mol Spectrosc 1997;182:239-59.

[8] Edwards DP, Lopez-Puertas M, and Mlynczak MG. Non-local thermodynamic equilibrium limb radiance from $\mathrm{O}_{3}$ and $\mathrm{CO}_{2}$ in the 9-11 $\mu \mathrm{m}$ spectral region. JQSRT 1994;54:389-407. 
[9] Mlynczak MG, and Drayson SR. Calculations of infrared limb emission by ozone in the terrestrial middle atmosphere, 2. emission calculations. J Geophys Res 1990;95:16,513-21.

[10] Russell III JM, Mlynczak MG, Gordley LL, Tansock J, and Esplin R. An overview of the SABER experiment and preliminary calibration results. In: Proceedings of SPIE Conference, Denver CO $1999 ; 3756: 277-86$.

[11] Remsberg EE., Russell III JM, Gille JC, Gordley LL, Bailey PL, Planet WG, and Harries JE, The validation of Nimbus 7 LIMS measurements of ozone. J Geophys Res 1984;89:5161-78.

[12] Remsberg EE, Burton J, Gordley L, Marshall BT, Bhatt P, and Miles T, Improvements in Nimbus 7 limb infrared monitor of the stratosphere ozone profiles as obtained with updated spectral line parameters and radiance algorithms. J Geophys Res 1995;100:16,727-33.

[13] Connor BJ, Siskind DE, Tsou JJ, Parrish A, and Remsberg EE, Ground-based microwave observations of ozone in the upper stratosphere and mesosphere. J Geophys Res 1994;99:16,757-70.

[14] Solomon S, Kiehl JT, Kerridge BJ, Remsberg EE, and Russell III JM, Evidence for non-local thermodynamic equilibrium in the $v_{3}$ mode of mesospheric ozone. J Geophys Res 1986;91:9865-76.

[15] Kaufmann M, Gusev OA, Grossmann KU, Martin-Torres GJ, Marsh DR, and Kutepov AA, Satellite observations of daytime and nighttime ozone in the mesosphere and lower thermosphere. J Geophys Res 2003;108:doi:10.1029/2002JD002800.

[16] Mertens CJ, Mlynczak MG, Lopez-Puertas M, and Remsberg EE, Impact of non-LTE processes on middle atmospheric water vapor retrievals from simulated measurements of 6.8 micrometer Earth limb emission. Geophys Res Lett 2002;29:2-1 to 2-4. 
[17] Pallister RC, and Tuck AF, The diurnal variation of ozone in the upper stratosphere as a test of photochemical theory, QJRMS 1983;109:271-84.

[18] Hitchman MH, and Leovy CB, Diurnal tide in the equatorial middle atmosphere as seen in LIMS temperatures. J Atmos Sci 1985;42:557-61.

[19] Finger FG, Gelman ME, Schmidlin FJ, Leviton R, and Kennedy VW, Compatibility of meteorological rocketsonde data as indicated by international comparison tests. J Atmos Sci 1975;32:1705-14.

[20] Remsberg EE, Kurzeja RJ, KV Haggard, Russell III JM, and Gordley LL, Description of data on the Nimbus 7 LIMS map archive tape—ozone and nitric acid. NASA Tech. Paper No. 2625, NTIS Springfield VA, 1986:71pp.

[21] Russell III JM, and Drayson SR, the inference of atmospheric ozone using satellite horizon measurements in the $1042 \mathrm{~cm}^{-1}$ band. J Atmos Sci 1972;29:376-90.

[22] Bhartia PK, McPeters RD, Mateer CL, Flynn LE, and Wellemeyer C, Algorithm for the estimation of vertical ozone profiles from the backscattered ultraviolet technique. J Geophys Res 1996;101:18,793-806.

[23] Bhartia PK, Wellemeyer CG, Taylor SL, Nath N, and Gopalan A, Solar backscatter ultraviolet (SBUV) version 8 profile algorithm. In: Proc. Quad. Ozone Symposium, Kos Greece 2004:295-296.

[24] Ahn C, Wellemeyer CG, Taylor SL, Labow GL, Bhartia PK, and McPeters RD, Validating V8 SBUV profile data with external data sources (microwave, lidar, and sonde). In: Proc. Quad. Ozone Symposium, Kos Greece 2004:513-14.

[25] Sun C-R, and Leovy C, Ozone variability in the equatorial middle atmosphere. J Geophys Res 1990;95:13,829-49. 
[26] Bhatt PP, Remsberg EE, Schmidlin FJ, Gordley LL, and Burton JC, On the determination of biases in satellite-derived temperature profiles. Geophys Res Lett 1994;21:1145-48.

[27] Schmidlin FJ, Repeatability and measurement uncertainty of the United States meteorological rocketsonde. J Geophys Res 1981;86:9599-603.

[28] Schmidlin FJ, Lee HS, and Michel W, The inflatable sphere: a technique for the accurate measurement of middle atmosphere temperatures. J Geophys Res 1991;96:22,673-82.

[29] Thomas RWL, and Holland AC, Simple relationship between the uv radiation backscattered by the earth's atmosphere and the vertical ozone profile. Appl Opt 1977;16:2581-3.

[30] McPeters RD, Miles T, Flynn LE, Wellemeyer CG, and Zawodny JM, Comparison of SBUV and SAGE II ozone profiles: implications for ozone trends. J Geophys Res 1994;99:20,513-24.

[31] Leovy CB, Sun C-R, Hitchman MH, Remsberg EE, Russell III JM, Gordley LL, Gille JC, and Lyjak LV, Transport of ozone in the middle stratosphere: evidence for planetary wave breaking. J Atmos Sci $1985 ; 42: 230-244$.

[32] Remsberg EE, Haggard KV, and Russell III JM, Estimation of synoptic fields of middle atmosphere parameters from Nimbus 7 LIMS profile data. J Atmos Ocean Tech 1990;7:689-705.

[33] Siskind DE, Connor BJ, Eckman RS, Remsberg EE, Tsou JJ, and Parrish L, An intercomparison of model ozone deficits in the upper stratosphere and mesosphere from two data sets. J Geophys Res 1995;100:11,191-201 
[34] Chandra S, Jackman CH, Douglass AR, Fleming EL, and Considine DB, Chlorine catalyzed destruction of ozone: implications for ozone variability in the upper stratosphere. Geophys Res Lett 1993;20:351-4. 


\section{Figure Captions}

Fig. 1. Zonal-mean cross section of LIMS V6, descending orbital node (or nighttime) ozone for January 1979. Contour increment is $0.5 \mathrm{ppmv}$. Note that the units for pressure-altitude are given either as $\mathrm{hPa}$ or $\mathrm{mb}$ in this paper, but that they are equivalent.

Fig. 2. Zonal mean of LIMS V6 minus V5 ozone (in \%) for November 8, 1978. Contour intervals are 5 percent and negative contours are dashed.

Fig. 3. Zonal mean of LIMS V6 minus V5 temperature (in K) for November 8, 1978. Contour increment is $1 \mathrm{~K}$; negative contours are dashed.

Fig. 4. Profile of standard deviation (SD in \%) for V6 ozone profiles along orbits and within $+/-5$ degrees of latitude centered about $30 \mathrm{~S}$. Results are from the ascending (open symbols) and descending (solid symbols) orbital nodes that had the minimum SDs of all orbits on February 1, 1979.

Fig. 5. (a) Zonal mean of ascending (day) minus descending (night) V6 ozone (in \%) for January 1979. Contour increment is $5 \%$, and negative contours are dashed. (b) As in (a), but for temperature with a contour increment of $1 \mathrm{~K}$.

Fig. 6. Representative ozone limb-path weighting functions for selected altitudes.

Fig. 7. Zonal mean comparisons of LIMS V6 ascending (day) ozone with SBUV V8 ozone (in DU) for selected atmospheric layers of March 15, 1979- (a) 1.6-1.0, (b) 4.05-2.54, (c) 10.1-6.4, and (d) 40.5-25.4 $\mathrm{hPa}$.

Fig. 8. Zonal mean cross section of LIMS V6 minus SBUV V8 ozone (in \%) as referenced to SBUV—(a) November 8, 1978, (b) March 15, 1979, and (c) May 6, 1979. Contour increment is 4\%. Dashed contours 
are negative and the zero and positive contours are solid. Values greater than $+12 \%$ are shaded dark;

values from $+8 \%$ to $+12 \%$ are shaded light.

Fig. 9. Zonal mean cross section of LIMS V6 temperatures for (a) November 8, 1978 and (b) May 6, 1979.

Contour increment is $5 \mathrm{~K}$.

Fig. 10. (a) Comparison of LIMS V6 (dashed) versus ECC sonde ozone (solid) at Hohenpeissenberg in units of partial pressure (nb) on March 14, 1979; (b) comparison of T(p) for the profiles in panel (a).

Fig. 11. As in Fig. 10(a), but for Wallops Island on March 11, 1979. Each of the four nearby LIMS profiles is shown for this comparison case.

Fig. 12. Polar plot of LIMS V6 ozone at $10 \mathrm{hPa}$ on January 27, 1979.

Fig. 13. Monthly, model minus LIMS V6 zonal mean ozone differences at $30 \mathrm{~N}$ (in \%) for nighttime in the upper stratosphere and lower mesosphere, as referenced to the LIMS ozone. Contour interval is $2 \%$.

Fig. 14. As in Fig. 13, but for 40S. 
Table 1-Precision and Accuracy Estimates (\%) for LIMS V6 Ozone Profiles

\begin{tabular}{|c|c|c|c|c|c|c|c|}
\hline \multirow[b]{2}{*}{ RANDOM } & \multicolumn{5}{|c|}{ Pressure-altitude $(\mathrm{hPa})$} & \multirow[b]{2}{*}{0.4} & \multirow[b]{2}{*}{0.1} \\
\hline & 100 & 50 & 10 & 3 & 1 & & \\
\hline Noise $(\mathrm{N} / \sqrt{5}$ or $0.45 \mathrm{~N})$ & 11 & 5 & 1.1 & 0.6 & 1.4 & 3 & 18 \\
\hline Residual Offset (30m) & 3 & 2 & 0.5 & -0.6 & -0.8 & -1 & -0.8 \\
\hline $\begin{array}{l}\text { a. Root-sum-square (or RSS } \\
\text { of noise and offset) }\end{array}$ & 11 & 5 & 1.2 & 0.8 & 1.6 & 3 & 18 \\
\hline b. Jitter (43 meters) & 16 & 12 & 3 & 2 & 2 & 1.5 & 1.0 \\
\hline $\begin{array}{l}\text { c. TOTAL PRECISION } \\
\text { (or RSS of } a \text { and } b \text { ) }\end{array}$ & 19 & 13 & 3.2 & 2.1 & 2.6 & 3.4 & 18 \\
\hline SYSTEMATIC & & & & & & & \\
\hline Calibration (1\%) & 5 & 4 & 3 & 1.5 & 1 & 0.5 & 0.2 \\
\hline Encoder Space $(1.5 \%)$ & 12 & 3 & 2 & -1.5 & -4 & -4 & -2 \\
\hline FOV Deconvolution & 5 & 5 & 5 & 5 & 5 & 5 & 5 \\
\hline Line Intensity (3\%) & 3 & 3 & 3 & 3 & 3 & 3 & 3 \\
\hline Line Halfwidth (10\%) & 2 & 2 & 3 & 3 & 2 & 2 & 2 \\
\hline Forward Model & 15 & 6 & 1 & 2 & 0 & 0 & 0 \\
\hline Temperature (from [2]) & 20 & 20 & 11 & 10 & 12 & 16 & 16 \\
\hline Aerosol Correction & 5 & 5 & 0 & 0 & 0 & 0 & 0 \\
\hline d. RSS of terms & 29 & 22 & 14 & 12 & 14 & 18 & 17 \\
\hline e. Side Lobes $(25 \%)$ & 14 & 9 & 2 & 3 & 6 & 20 & 31 \\
\hline ACCURACY & & & & & & & \\
\hline f. RSS of $a$ and $d$ & 31 & 23 & 14 & 12 & 14 & 18 & 25 \\
\hline g. RSS of $\mathrm{c}$ and d & 34 & 26 & 14 & 12 & 14 & 18 & 25 \\
\hline h. Row g w/o $\mathrm{T}(\mathrm{p})$ bias & 21 & 9 & 9 & 7 & 7 & 8 & 6 \\
\hline i. RSS of c, d, and e & 37 & 28 & 14 & 12 & 15 & 27 & 40 \\
\hline
\end{tabular}




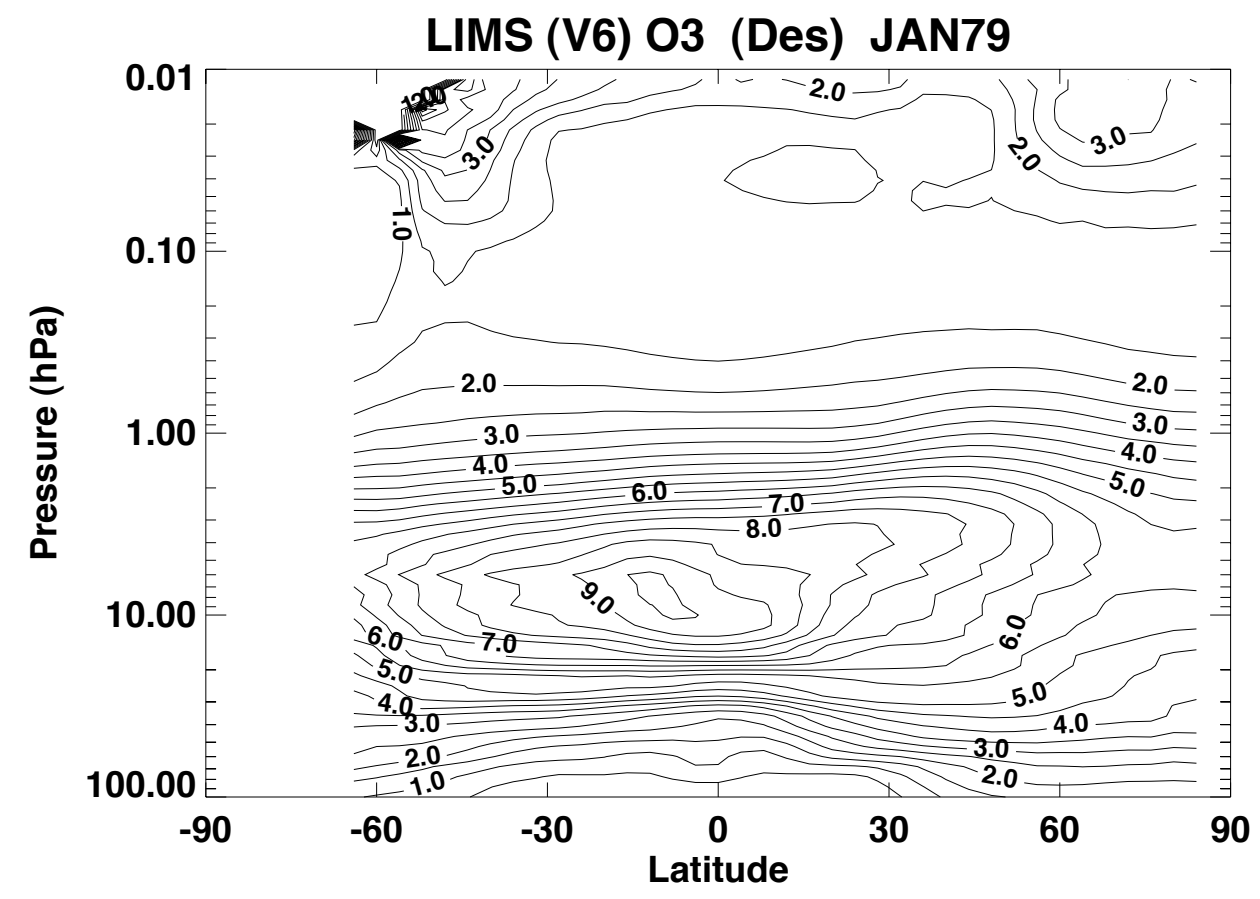




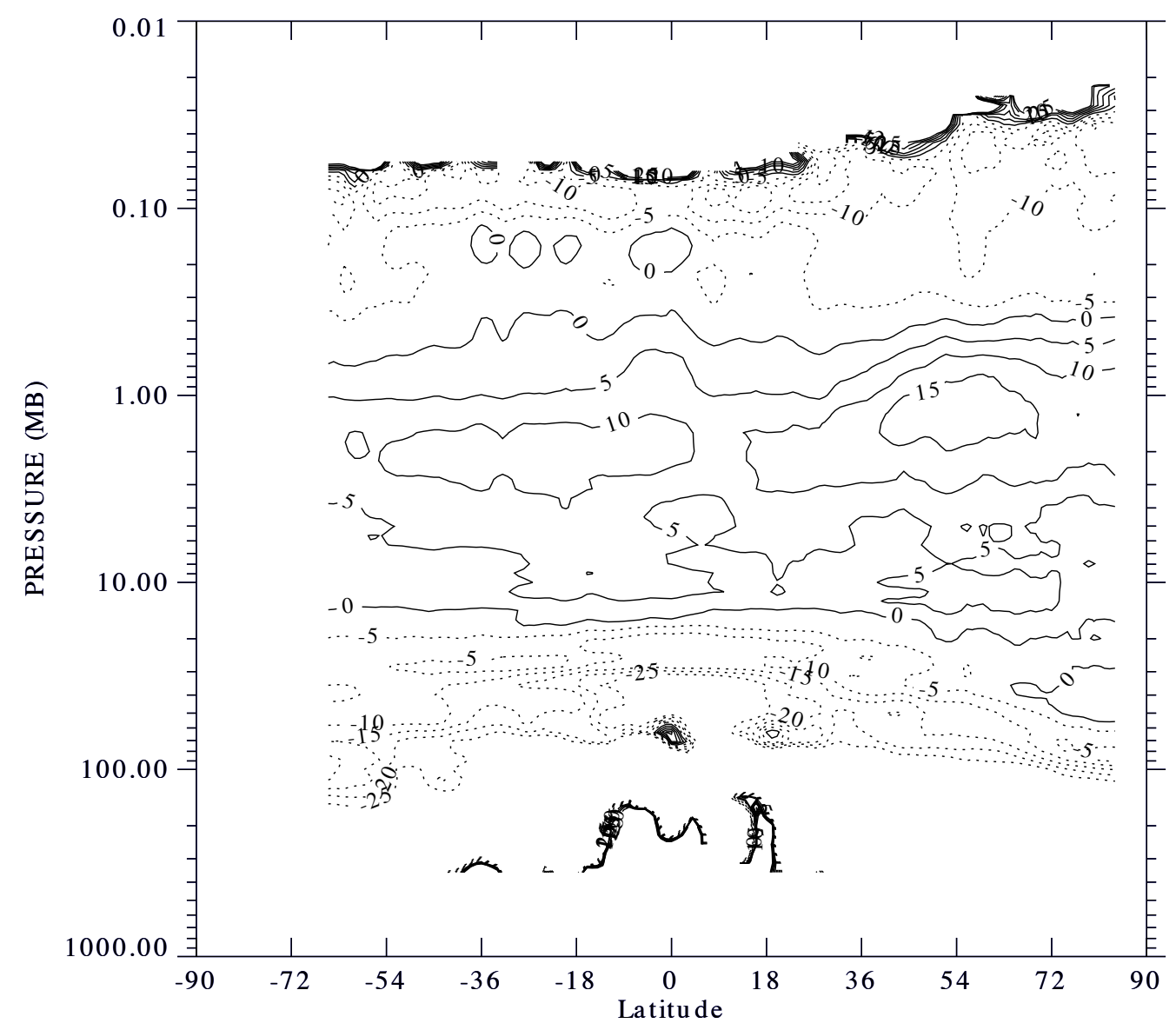




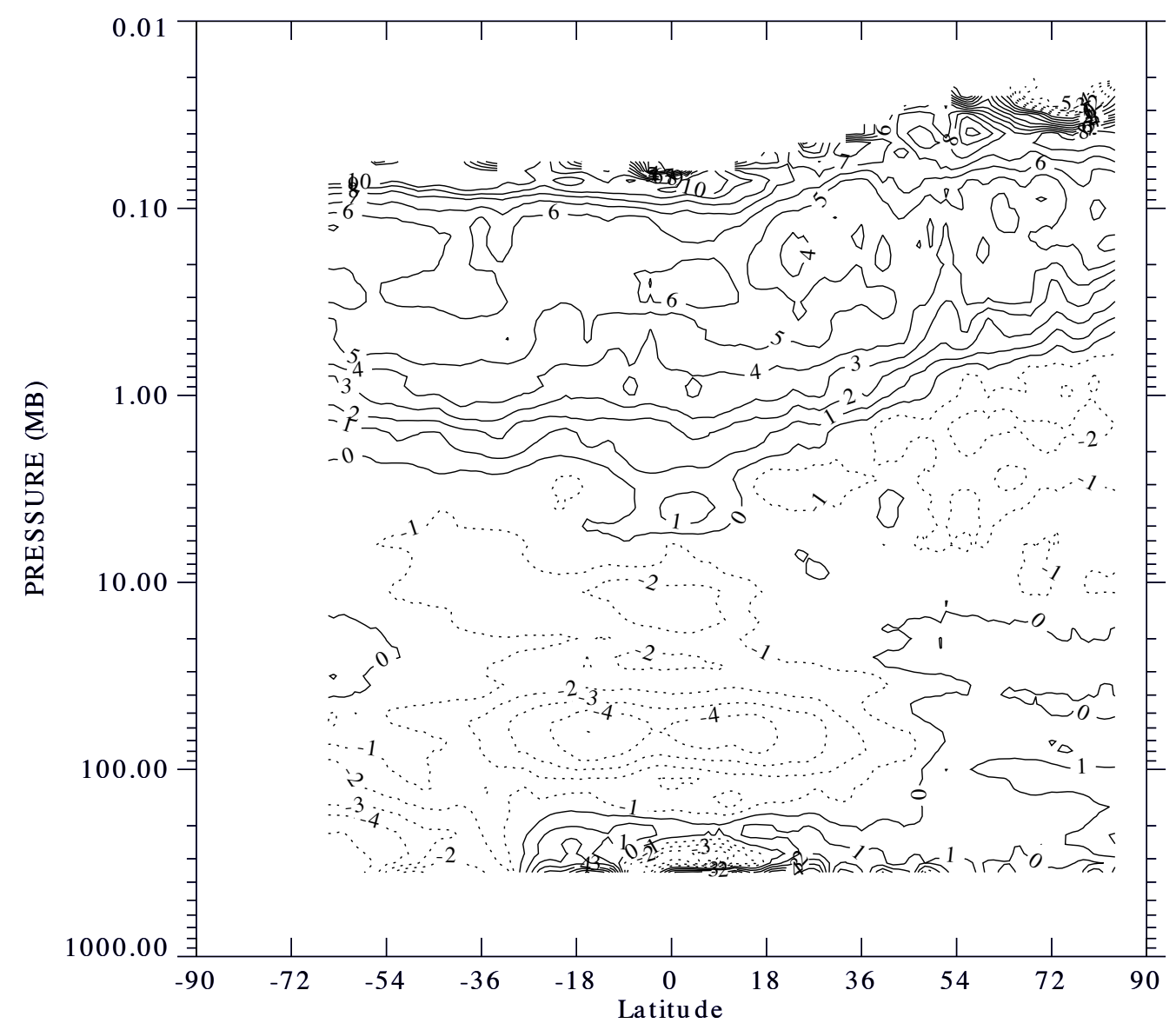




\section{LMS Ozone Precision 02/01/1979 305}

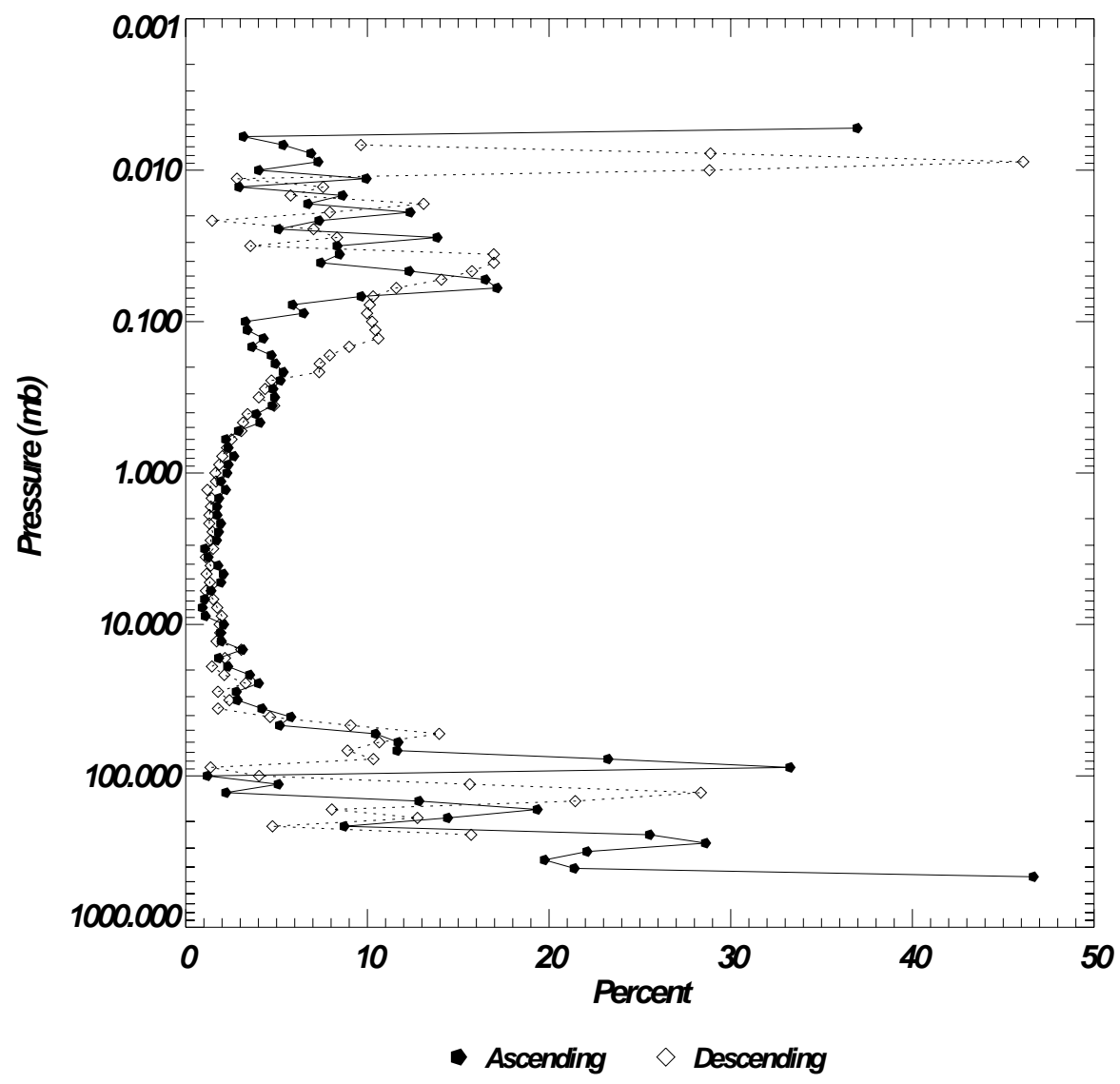




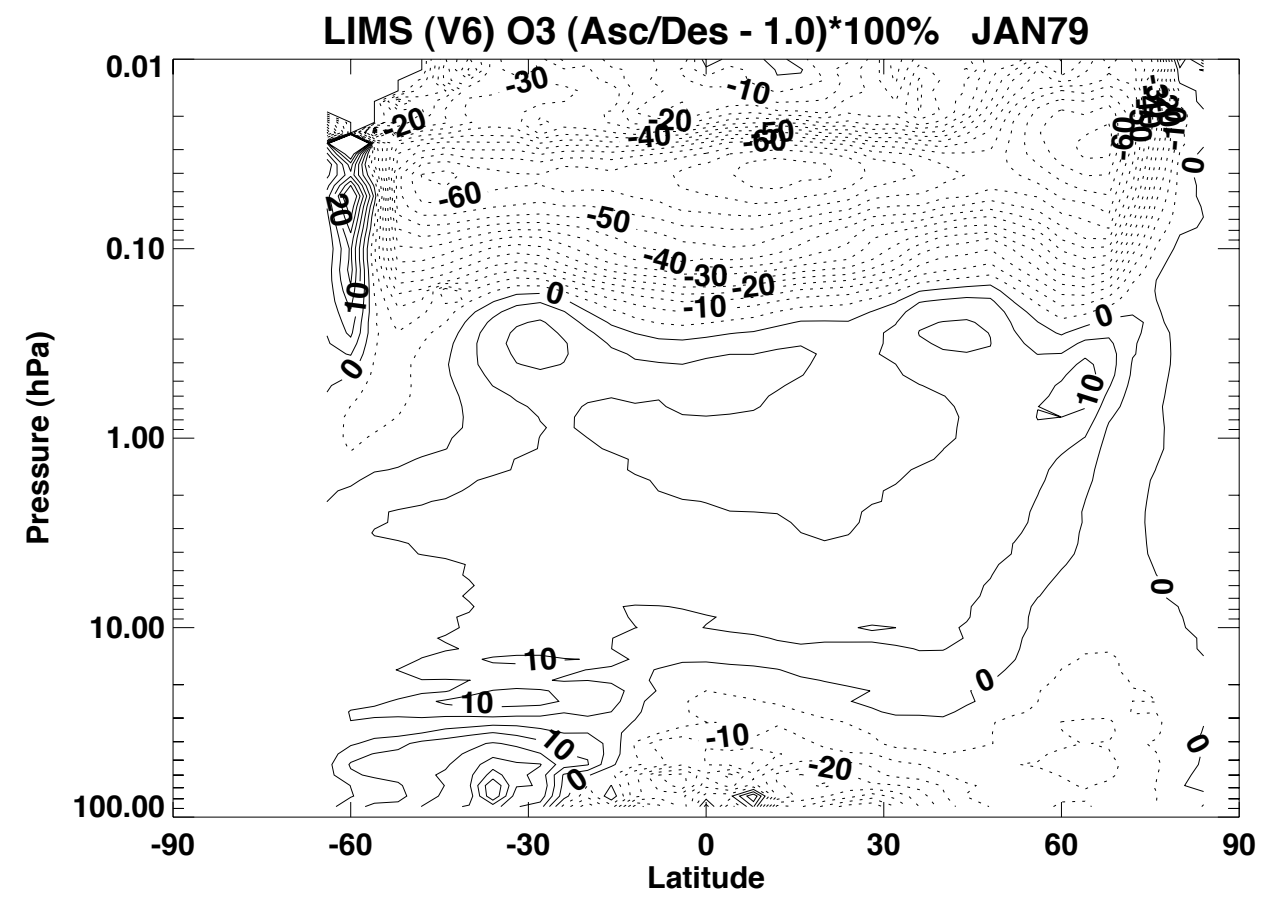




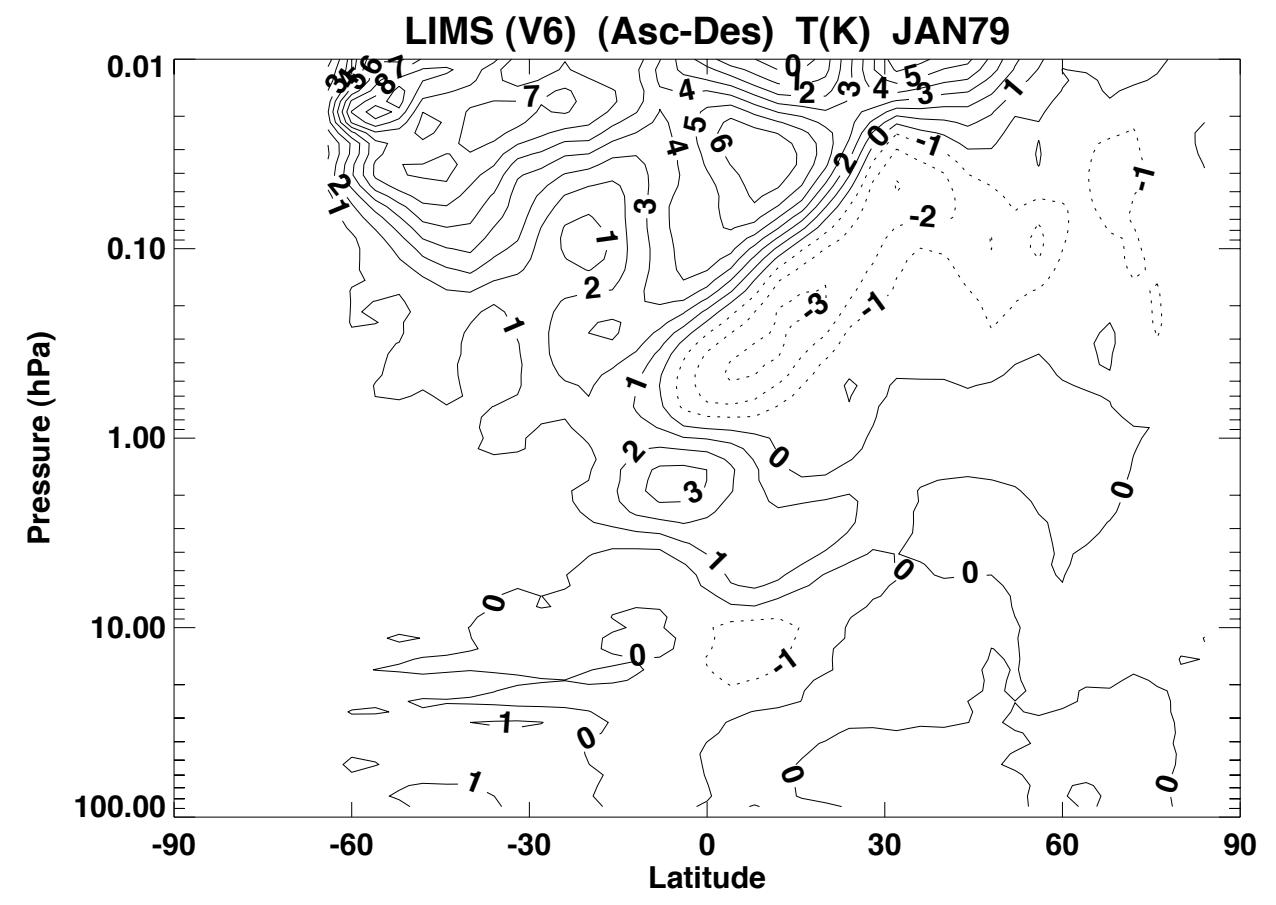




$$
\mathbb{1}
$$




\section{ZONAL MEAN LAYER OZONE 03-15-1979}

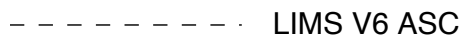

SBUV V8
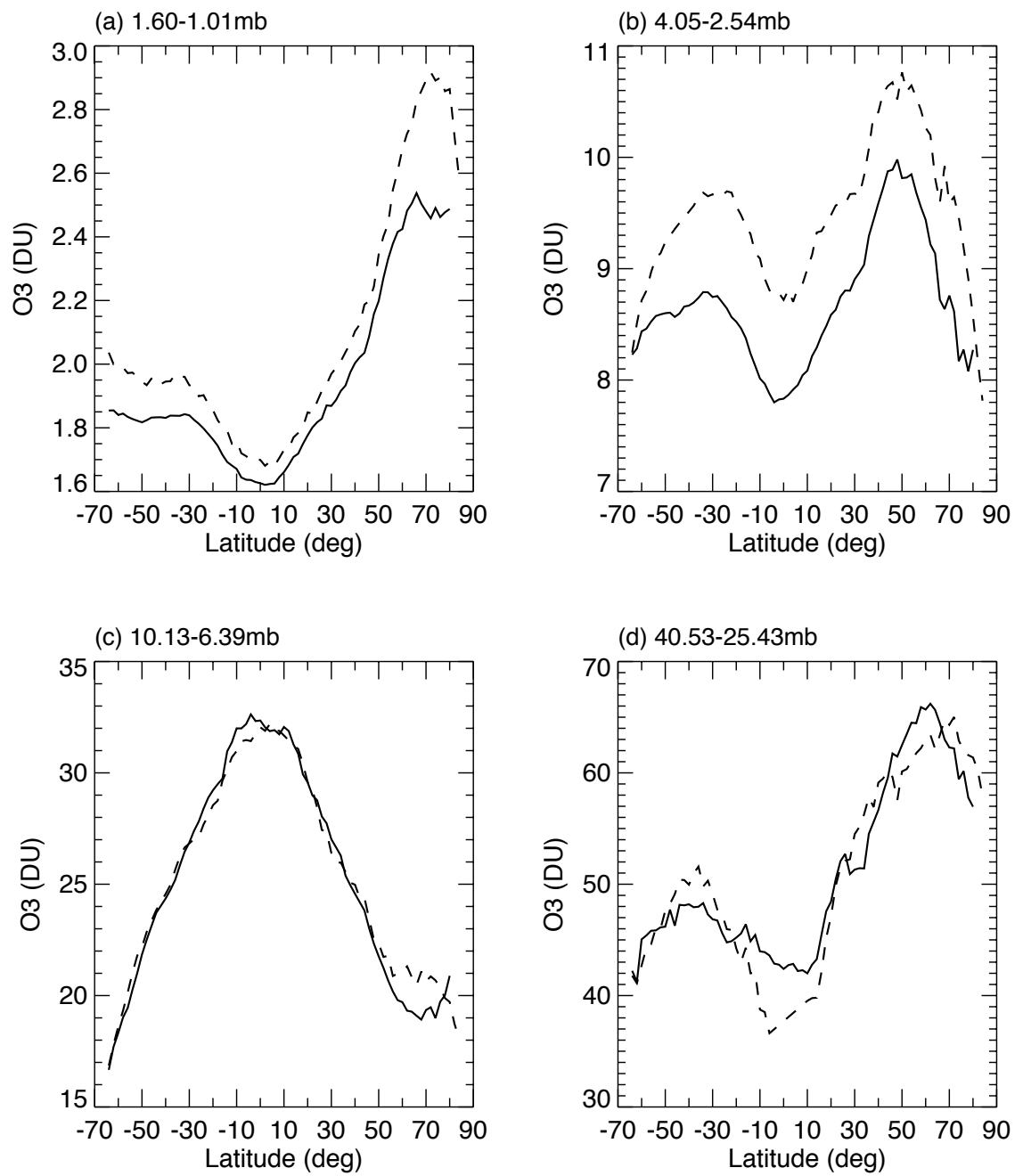


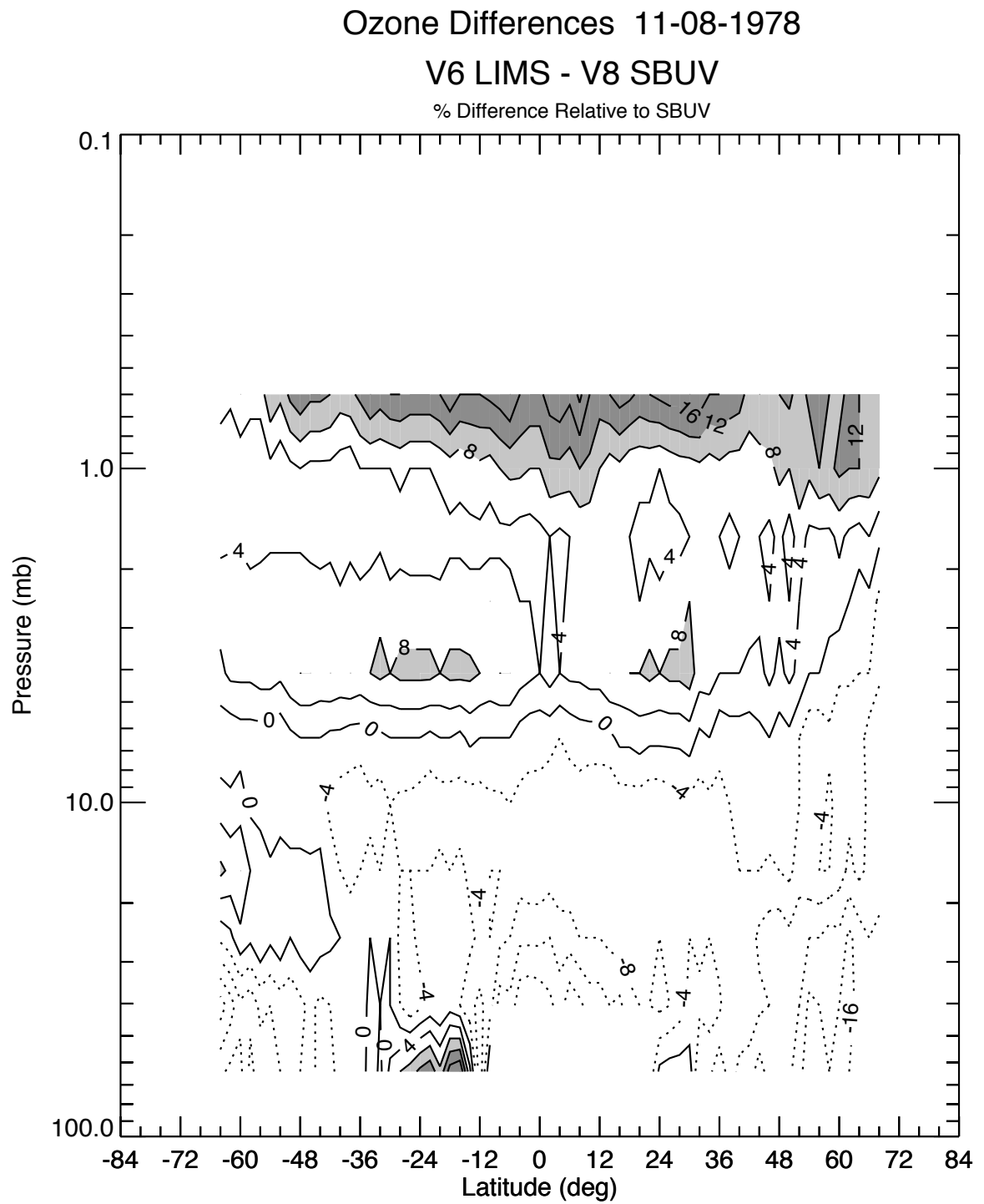




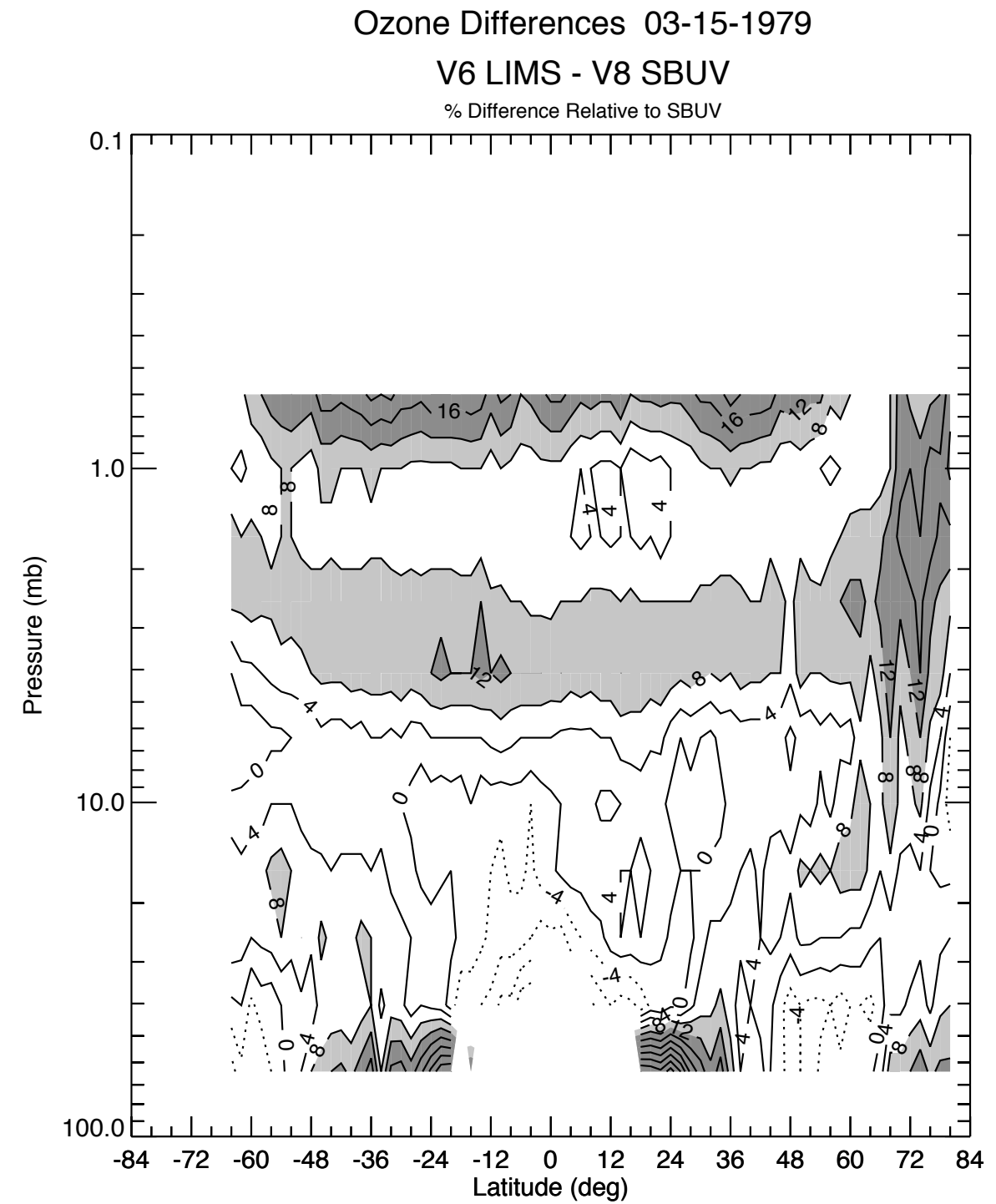




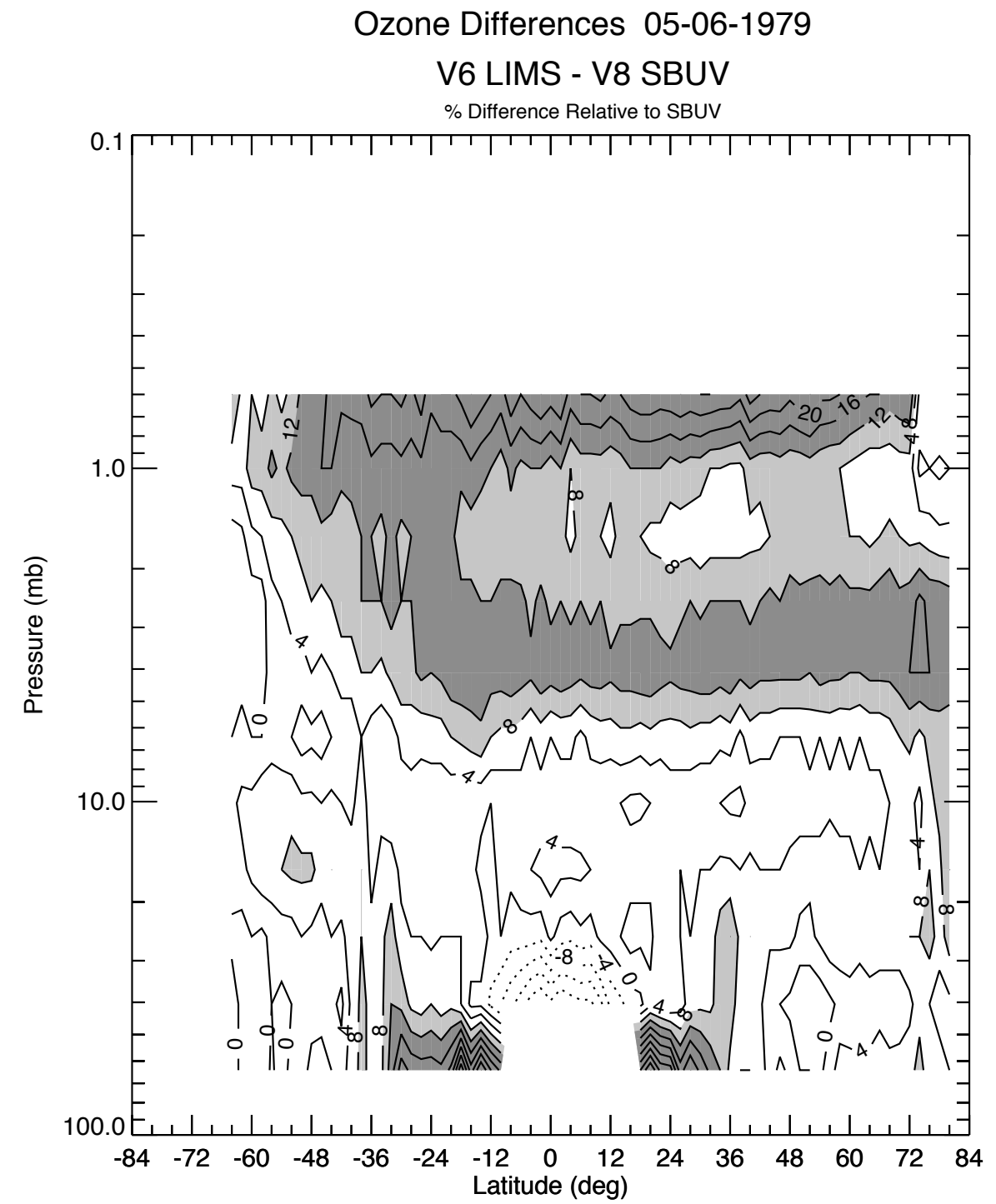




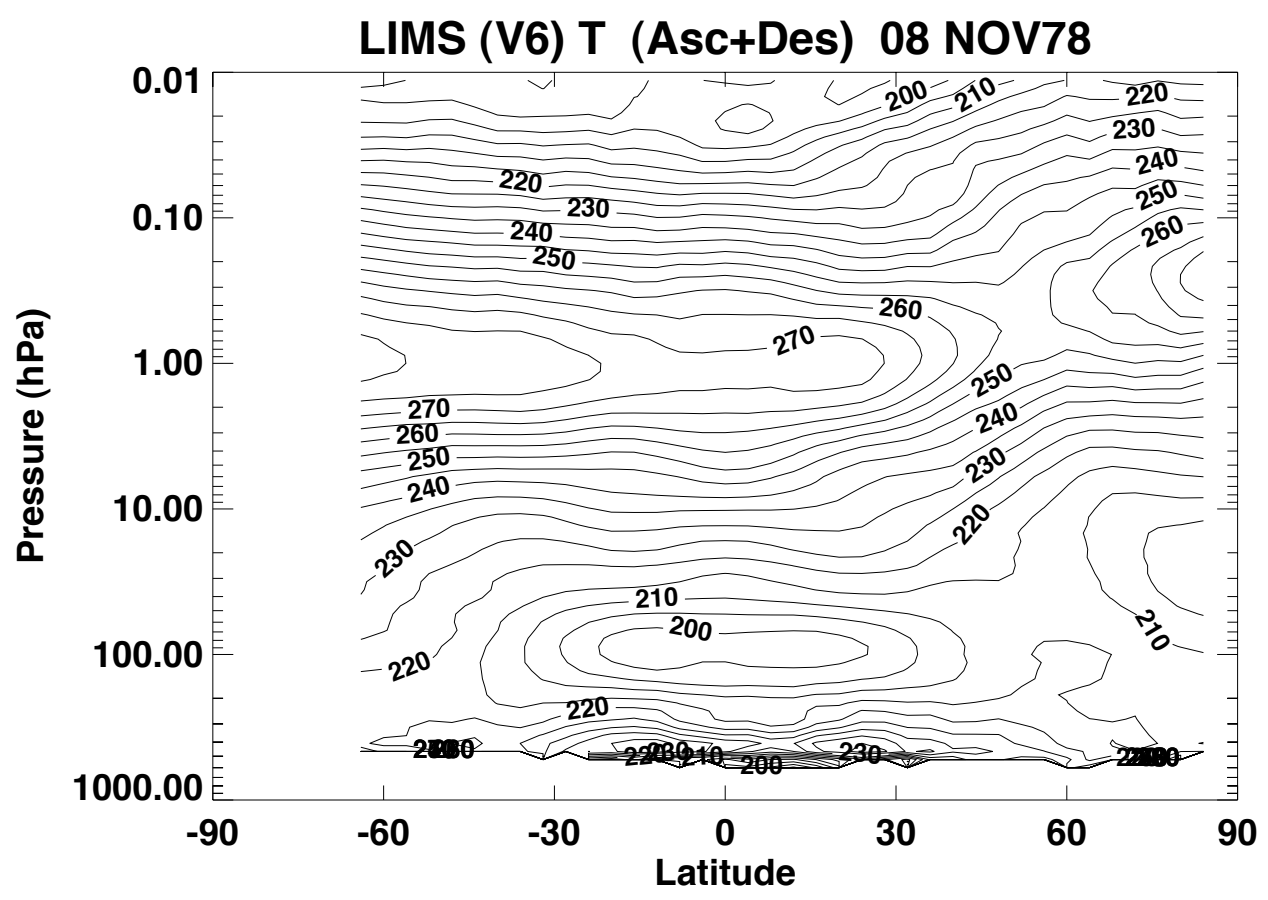




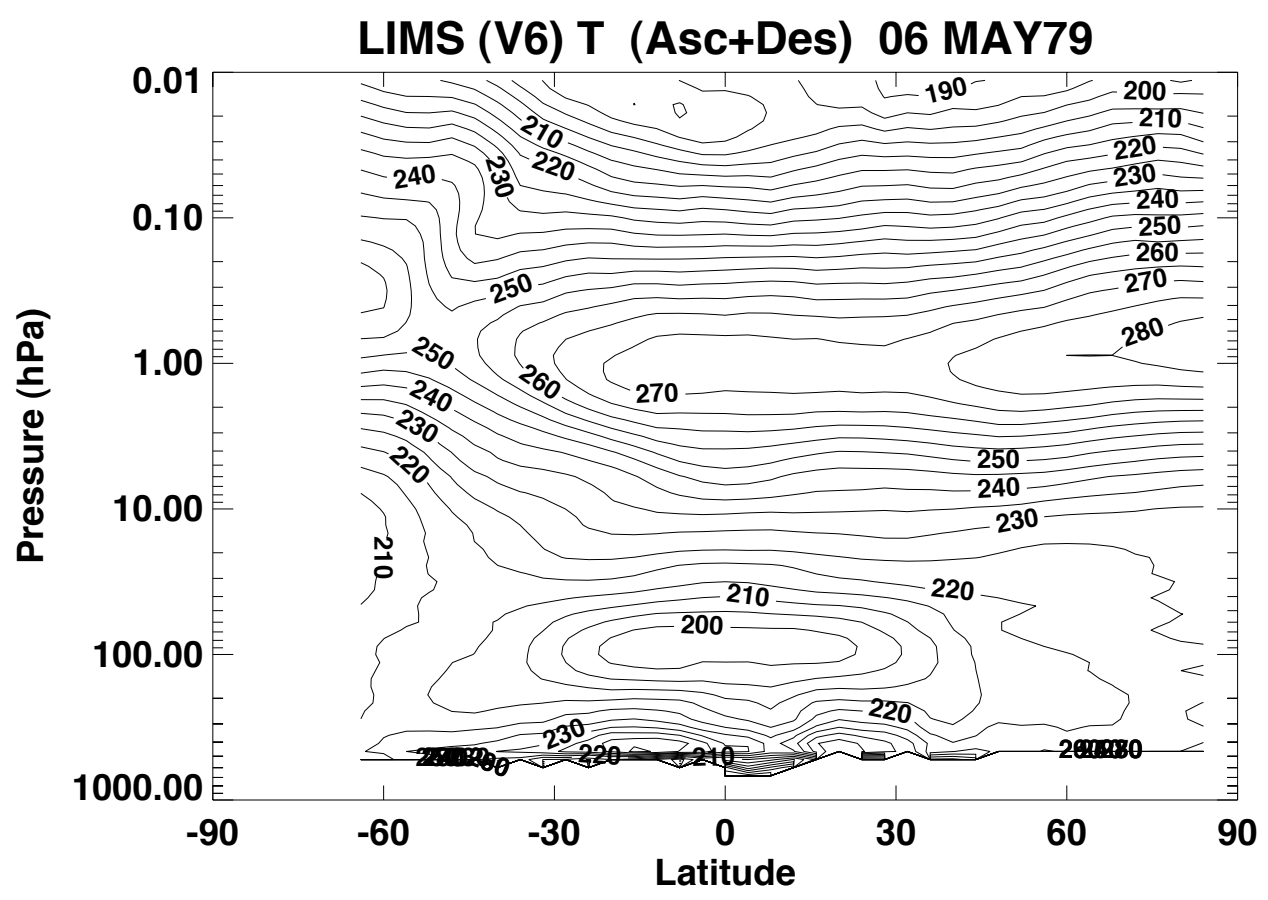




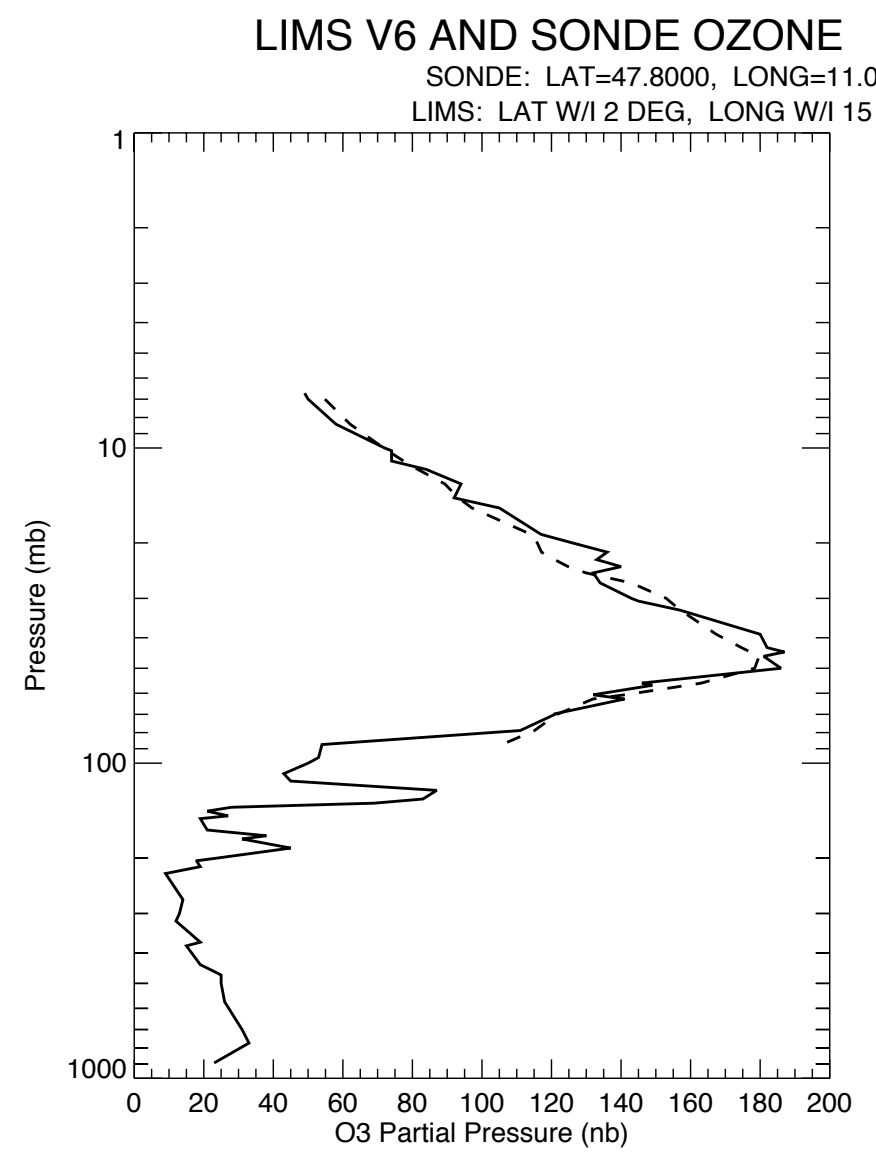

03-14-1979

DEG

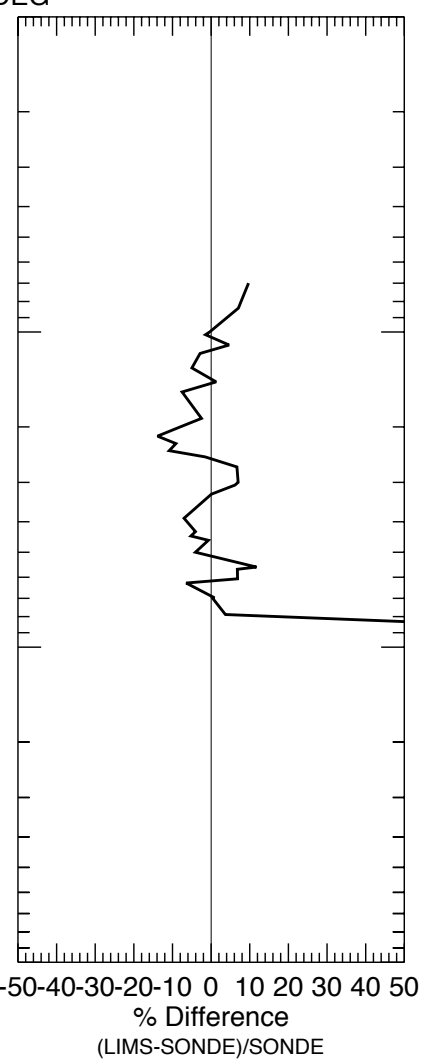




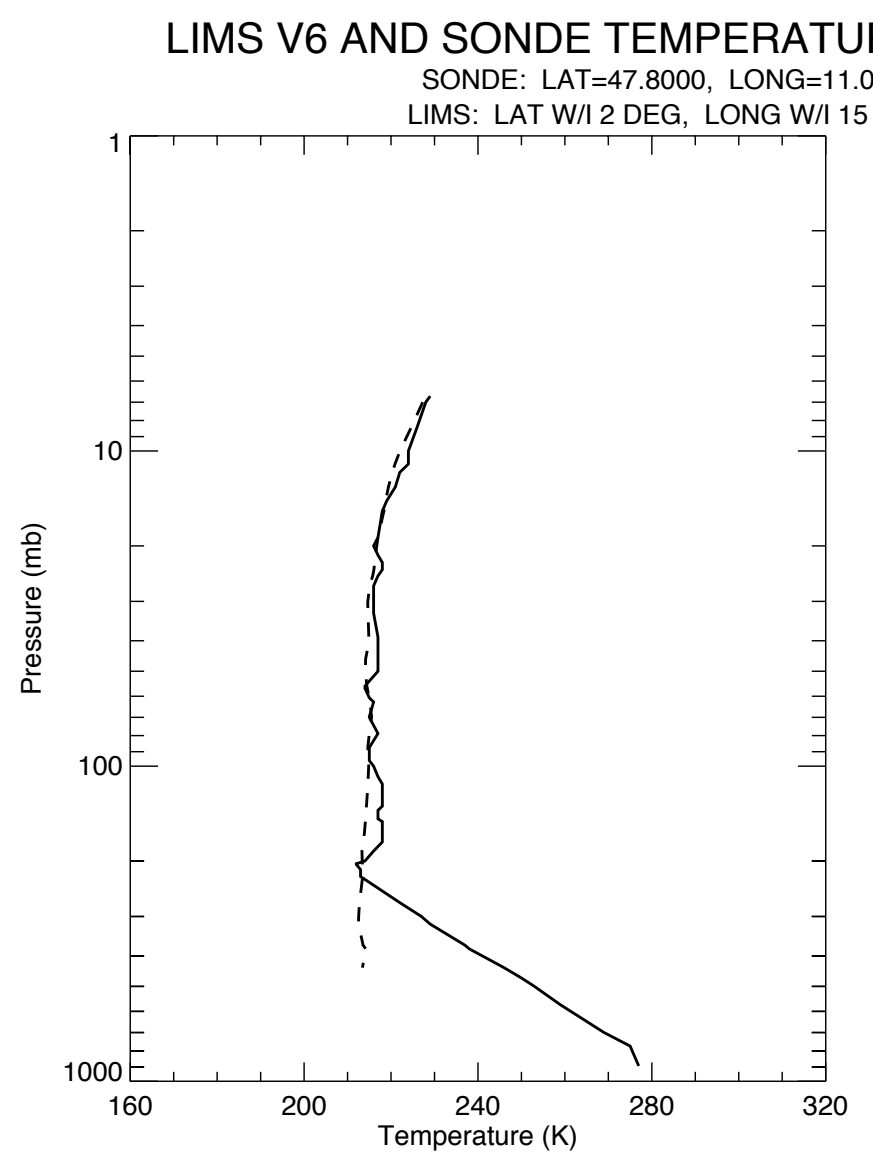

RE 03-14-1979 DEG 


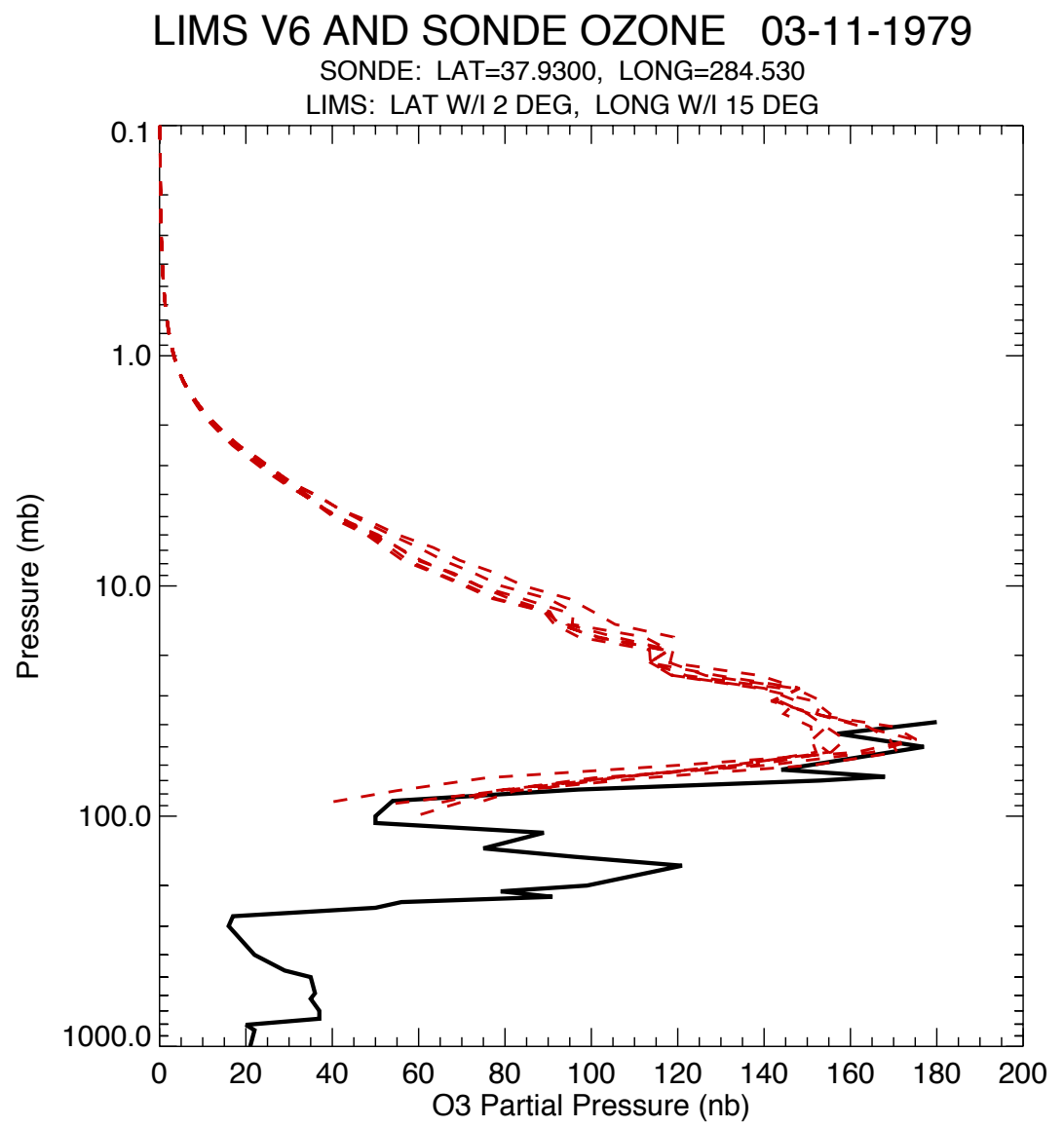




\section{LIMS V6 Ozone (ppmv) Northern Hemisphere 10.0mb 27 Jan 1979}

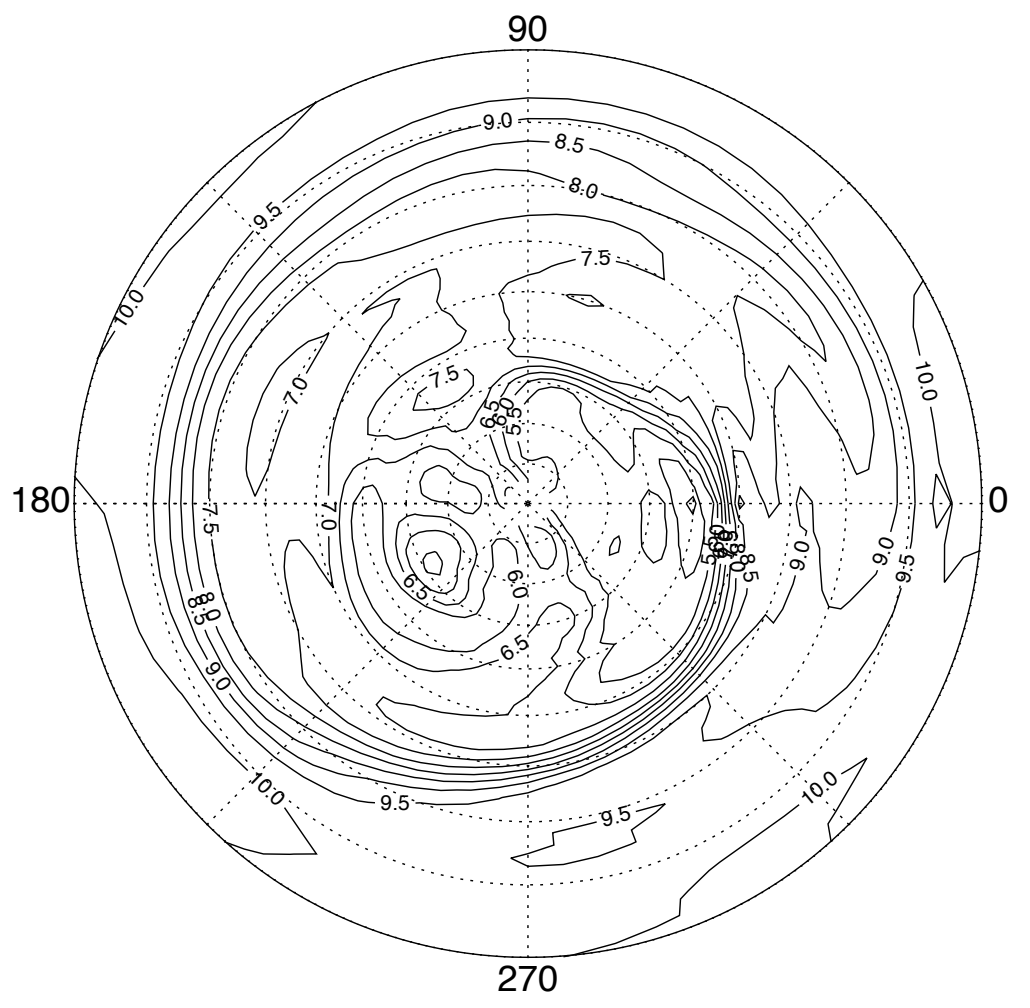




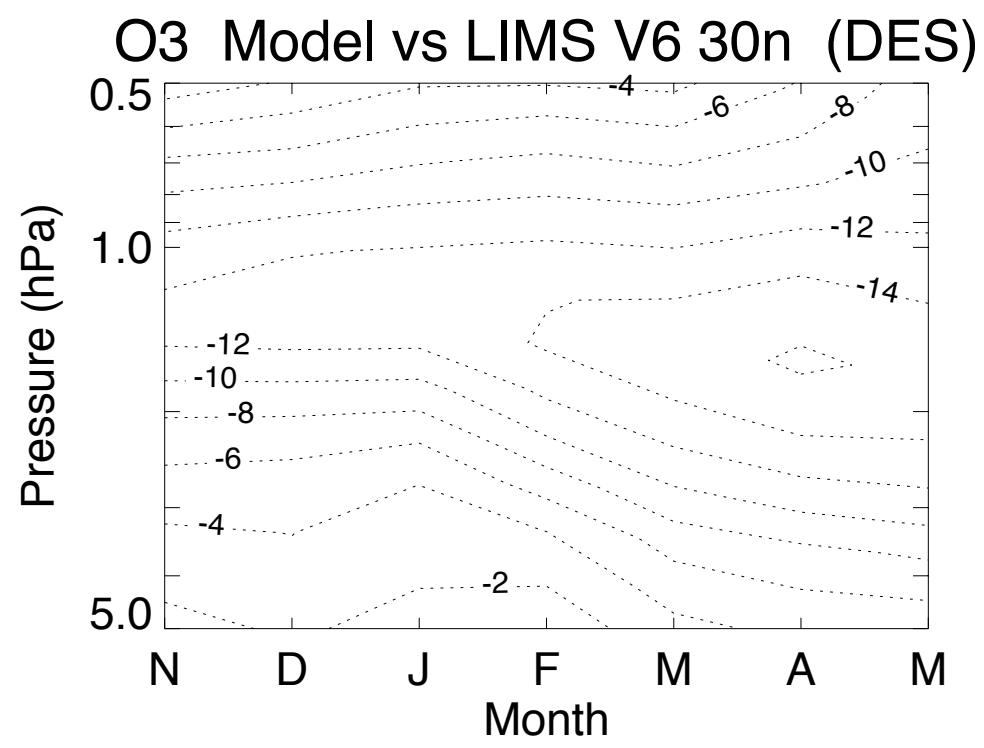




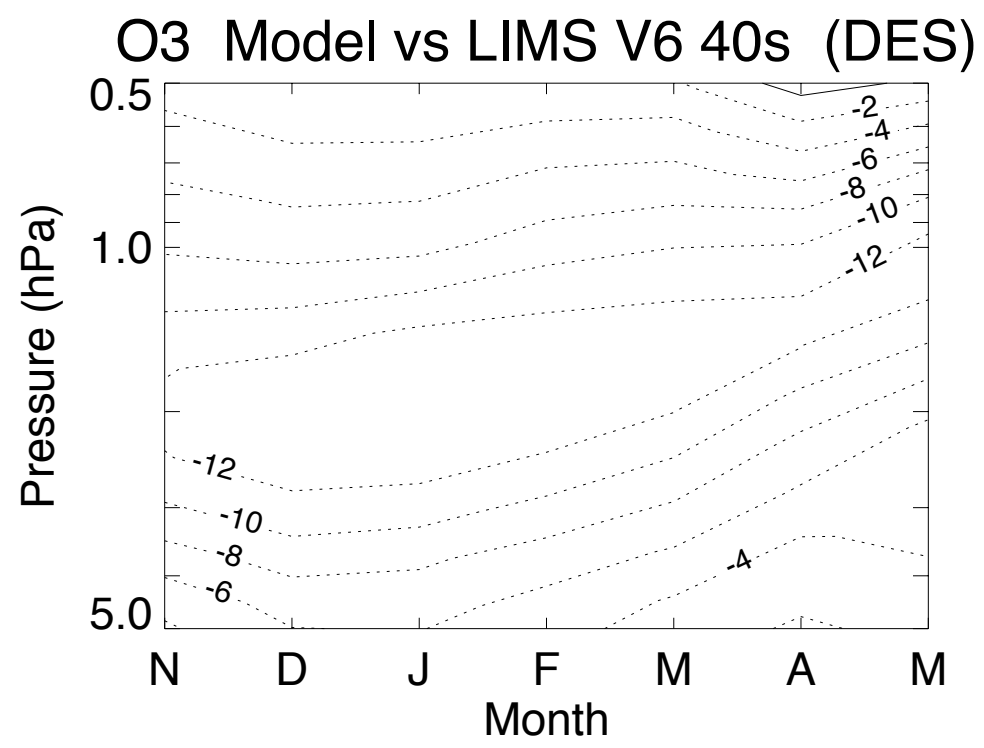

